\title{
Air Pollution Abatement Costs under the Clean Air Act: Evidence from the PACE Survey
}

\author{
Randy A. Becker \\ Center for Economic Studies \\ U.S. Bureau of the Census
}

November 2001

The author has benefited from the helpful comments and suggestions of Wayne Gray and Daniel Millimet, as well as numerous seminar and conference participants at the Center for Economic Studies, Research Triangle Institute, Southern Methodist University, the 2000 NBER Summer Institute, and the 50th International Atlantic Economic Conference. The opinions and conclusions expressed herein are those of the author and do not necessarily represent the views of the Bureau of the Census. This paper has been screened to ensure that it does not disclose any confidential information. All errors are my own. 


\begin{abstract}
This paper uses establishment-level data from the U.S. Census Bureau's Pollution Abatement Costs and Expenditures (PACE) survey to investigate the effects of air quality regulation on the air pollution abatement capital expenditures and operating costs of manufacturing plants from 1979-1988. Results, based on some 90,000 observations, show that heavy emitters of the "criteria" air pollutants (covered under the Clean Air Act) had significantly larger APA costs, and those subject to greater "local" regulation (due to county NAAQS non-attainment) had expenditures that were greater still. The local regulation of a particular air pollutant generally resulted in hundreds of thousands of dollars (or more) of additional costs, with larger establishments and capital expenditures disproportionately affected. Federal and state environmental standards appear to have played a notable role, particularly in industries producing chemicals, petroleum, primary metals, and nonmetallic minerals. The findings of this paper support those of several recent studies.
\end{abstract}

KEYWORDS: costs, environmental, regulation, air, pollution, abatement, county, NAAQS, nonattainment, manufacturing 


\section{INTRODUCTION}

There has been, as of late, increased contemplation of the various costs associated with the Clean Air Act. A recent U.S. Supreme Court case tested whether the Environmental Protection Agency can and should take into account potential costs to affected parties when setting the national ambient air quality standards that all areas of the country are required to meet. Despite arguments from several industry groups and many prominent economists to allow the EPA to conduct benefit-cost analyses, as required for other types of regulation, the court unanimously ruled that, under the Clean Air Act, the agency must only consider the public health benefits of its air quality regulations and not, for example, any of the compliance costs they impose on businesses. Opponents of this decision have promised to fight on, vowing to take their case to Congress and the Bush administration and demand that the statute be reworded to allow for the consideration of costs.

This paper examines some of the costs to manufacturing plants of the Clean Air Act (and its amendments) from 1979-1988, using establishment-level data on environmental expenditures from the Census Bureau's Pollution Abatement Costs and Expenditures (PACE) survey. The effects of air quality regulation, in terms of higher operating costs and additional capital expenditure for air pollution abatement, are identified by using the spatial variation in regulatory stringency, between counties that are in non-attainment versus attainment of federal air quality standards, for establishments that are and aren't heavy emitters of the targeted pollutants. The analyses also control for various establishment characteristics and county characteristics thought to be important determinants of plant-level environmental expenditures.

Results, based on some 90,000 observations, suggest that establishments subject to greater regulation during this period, indeed, generally had higher levels and probabilities of air pollution abatement capital expenditures and operating costs. Effects, in relative terms, were greater on plants' capital expenditures than on their operating costs, though additional outlays of each ranged in the hundreds of thousands of dollars for the average regulated plant in this sample. It is the existence of such costs that underlie the findings of several recent economic studies. Interestingly, state and federal standards appear to have played a much larger role in determining the air pollution abatement expenditures of heavy polluters than did "local" regulation (due to county non-attainment status). Moreover, cases are found where heightened local regulation had no apparent effect, and reasons for why this might be the case are discussed. 
The regulatory implications of establishment size, age, industry, and corporate structure are also explored.

The paper proceeds as follows. In the next section, I offer some background discussion, including a brief overview of air quality regulation in the United States, a review of the recent literature, and the motivation for this current study. This is followed by a section describing data sources and empirical specifications. Section IV contains my empirical results, and Section V offers some concluding remarks. Note that some of the details regarding data construction and such are contained in an appendix to this paper.

\section{BACKGROUND}

In accordance with the Clean Air Act [CAA] of 1970, the U.S. Environmental Protection Agency [EPA] has set national ambient air quality standards [NAAQS] for six pollutants that all areas of the country are required to meet. These so-called "criteria" air pollutants, considered harmful to both public health and the environment, are: tropospheric ozone $\left(\mathrm{O}_{3}\right)$, total suspended particulates (TSP), carbon monoxide (CO), sulfur dioxide $\left(\mathrm{SO}_{2}\right)$, nitrogen dioxide $\left(\mathrm{NO}_{2}\right)$, and lead $(\mathrm{Pb})$. The standards set for each of these pollutants - maximum permissible concentrations essentially - are science-based criteria meant to (above all else) protect human health. Indeed, in setting these NAAQS, the EPA must only consider the health benefits of the standards and is legally prohibited from taking into account any potential costs arising from their implementation.

A stipulation of the 1977 amendments to the CAA is that, each year, every county in the United States be officially designated as being either in- or out-of-attainment of the federal standard for each of these air pollutants. Counties that are in non-attainment of a standard are required by law to bring themselves into attainment or face potential federal sanctions. These sanctions may include the withholding of federal grant monies (e.g., highway construction funds), direct EPA enforcement and control, bans on the construction of new establishments (with the potential to pollute), and so forth. Consequently, pollution sources in non-attainment areas - particularly industrial sources that emit the offending pollutant(s) - are much more heavily regulated than similar sources in attainment areas.

For example, in non-attainment areas, industrial plants with the potential to pollute are generally subject to more stringent, more costly technological requirements on their capital equipment, including the installation of additional air pollution abatement equipment (such as 
filters, scrubbers, precipitators, and the like). In addition to higher capital expenditures, these establishments may face higher operating costs as well — in terms of additional staff and/or staff-time; more (and/or more expensive) materials, fuels, and energy; additional capital depreciation, maintenance costs, and/or leasing of equipment; services of outside contractors to perform environmental tasks; and so forth. Regulatory compliance may also necessitate redesigns in production processes, which can be quite costly, especially if output must be suspended in the interim. In general, state and local regulators have discretion in how they choose to bring non-attainment areas into attainment, including which sources to regulate and what to require of them. These requirements are formalized into State Implementation Plans, which are submitted to EPA for review and approval (see Becker 1998).

A recent Supreme Court case - American Trucking Associations Inc., et al. v. Administrator of Environmental Protection Agency, et al. (No. 99-1426 \& 99-1257; argued November 7, 2000; decided February 27, 2001) - has renewed discussion of and interest in the various costs incurred by industry as a result of the Clean Air Act. At the crux of this case were the stricter new NAAQS for particulates and ozone issued by the EPA in July 1997. In May 1999, the U.S. Court of Appeals for the District of Columbia Circuit struck down these new air quality standards on the grounds that the existing interpretation of the CAA left the EPA with no "intelligible principle" with which to set NAAQS, thereby effecting "an unconstitutional delegation of legislative power" to an executive branch agency.

Part of the predicament here is that in 1970, when the EPA was first instructed to set ambient air quality standards, it was believed that there were concentration thresholds for these various air pollutants below which there would be no ill effects on human health, and Congress surely thought that, with the Clean Air Act, it was telling EPA to find these thresholds. Science has since found, however, that many pollutants (ozone and particulates among them) have no truly safe levels above zero. If, as required by the CAA, the EPA must only consider health benefits when setting standards, how can it then legitimately justify setting a non-zero standard for these pollutants (as it has done)? And Congress certainly never meant to give EPA the power to regulate away entire industries, as certain interpretations of the CAA might support.

\footnotetext{
${ }^{1}$ Apart from these costs, incurred "on the shop floor" as it were, there are other, more direct regulatory costs that industrial plants in non-attainment areas are also more likely to face. For one, such plants are much more likely to be inspected and (hence) fined than are similar facilities in attainment areas. In addition, plants in non-attainment areas (particularly those seeking to expand their operations) may be required to purchase pollution offsets from other establishments in the area. Such costs will not be explored in this paper.
} 
One way out of this constitutional quagmire is to allow the EPA to tradeoff benefits with costs, in a cost-benefit framework, as the setting of many other federal regulations require. The D.C. Court of Appeals however, in the same decision that struck down the new NAAQS, upheld its longstanding ruling in Lead Industries Association v. EPA (499 U.S. 1042 (D.C. Cir. 1980)) that the CAA prohibits the EPA from considering anything but benefits. American Trucking Associations and the other industry groups in the case appealed this aspect of the decision to the Supreme Court, while the EPA appealed the non-delegation ruling as well as some other technical matters.

Much debate surrounded the merits of these two interrelated cases. Perhaps most notably, the AEI-Brookings Joint Center for Regulatory Studies, together with over forty prominent economists, filed an amici curiae (Friend of the Court) brief with the Supreme Court recommending that it "allow the Environmental Protection Agency to consider costs in setting nationwide air quality standards, so that this information can be considered along with benefits and any other relevant factors in setting a standard" (AEI-Brookings, 2000). To not allow this ("if at all possible given the relevant legal authorities") is in their opinion "economically unsound."

In the end, however, the Supreme Court ruled that the Clean Air Act does not unconstitutionally concede power to the EPA, and it upheld the lower court's decision requiring the EPA to ignore all factors other than health effects when setting standards. This is not necessarily the end of this matter however. The new standards can still be challenged in the Appeals Court as "arbitrary and capricious", and the United States Chamber of Commerce, in particular, one of the many plaintiffs here, has said that it would take its case to Congress and the new Bush administration and fight for a rewording of the statute that would explicitly allow costs to be considered by the EPA at the standard-setting stage.

There have been, in the last few years, a number of studies that have examined the impact of the Clean Air Act - and county non-attainment status in particular - on manufacturing industries. Henderson (1996), for example, finds that, all else being equal, the number of plants in certain industries emitting volatile organic compounds (VOC) - which, along with $\mathrm{NO}_{2}$, lead to the formation of tropospheric ozone - was at least $7 \%$ lower in ozone non-attainment counties between 1978-1987, compared to attainment counties, suggesting that heavier regulation significantly impacts plant location decisions. Kahn (1997) finds that counties in TSP non- 
attainment had 14\% lower growth in manufacturing employment between 1982-1988, controlling for the level of non-manufacturing employment growth. Greenstone (2001) also finds that county non-attainment status (across four different criteria pollutants) reduced the level of manufacturing activity (employment, investment, and output) in those respective counties. According to one estimate, non-attainment counties lost over 590,000 manufacturing jobs between 1972 and 1987 - a direct result of being more heavily regulated.

Becker and Henderson (2000) examine the effects of ozone non-attainment status on the behavior of manufacturing plants in heavy VOC-emitting industries from 1963-1992. A key finding in that study is the $25-45 \%$ drop in the number of new plants in these industries opening in non-attainment counties, all else being equal, again suggesting that plant location is sensitive to the additional regulatory costs in those areas. ${ }^{\square}$ The authors also explore the role of county ozone non-attainment on the survival and investment patterns of plants in those polluting industries.

Collectively, this literature has found a variety of significant effects on industry behavior vis-à-vis county non-attainment status, attributable presumably to stricter environmental regulations and higher compliance costs. Becker and Henderson (2001) is an attempt to actually quantify some of these costs. Using plant-level data from the Censuses of Manufactures, the authors estimate average total cost functions for plants in two industries known to be large emitters of ozone precursors. They find that, ceteris paribus, total operating costs are indeed higher for plants located in ozone non-attainment counties. For example, relatively new plants (0-4 years of age) in the industrial organic chemicals industry (SIC 2865-9) in ozone nonattainment areas had operating costs that were roughly $17 \%$ higher than those for similar plants in attainment areas. A limited analysis using data from the 1992 PACE survey, however, finds little to no effect of non-attainment status on air pollution abatement costs.

Here, I revisit the costs of air quality regulation on manufacturing plants. Compared to Becker and Henderson (2001), mine will be a more comprehensive look at county nonattainment status and air pollution abatement costs using data from the PACE survey. For one, the present study will look at a longer time period than did the previous. Furthermore, I will consider all industries (allowing for "control” groups) and all criteria air pollutants (besides just ozone and ozone precursors). My analysis also allows effects to differ for plants that are large

\footnotetext{
${ }^{2}$ List and McHone (2000) find similar effects for a sample of new plants in New York State from 1980-1990.
} 
emitters of multiple air pollutants and/or are located in counties that are in non-attainment vis-àvis multiple pollutants. The next section describes my empirical specification and the data sources used.

\section{DATA AND EMPIRICAL SPECIFICATION}

An alternative to inferring the costs of regulation from a plant's total costs - which is much of the analysis in Becker and Henderson (2001) - is to directly examine the environmental costs incurred by the plant. One source of such information is the Census Bureau's Pollution Abatement Costs and Expenditures (PACE) survey. Conducted annually since 1973, the PACE survey's primary purpose through the years has been to collect timely information from manufacturing establishments on capital expenditures and operating costs associated with pollution abatement efforts. Data from the survey are tabulated and published by the Census Bureau, by industry, state, type of cost, type of pollutant, and combinations thereof. ${ }^{\square}$ The PACE survey was discontinued recently (1995-1998, 2000-2001), but there is renewed interest in collecting it again on a more regular basis, beginning perhaps with the 2002 reference year.

In this study, I use the establishment-level data from the PACE surveys of 1979-1982, 1984-1986, and 1988. 4 My variables of interest here are air pollution abatement capital expenditure (including items such as scrubbers, filters, precipitators, and so forth, as well as relevant capital associated with "production process enhancements") and air pollution abatement operating costs (which includes relevant salaries \& wages, parts \& materials, fuel \& electricity, capital depreciation, contract work, equipment leasing, etc.). To this I merge data that these plants may have reported in the (contemporaneous) Annual Survey of Manufactures (ASM). The ASM data provide me with some important, basic information on these plants, including total capital expenditure and total operating costs (which presumably subsume the above environmental expenditures), as well as establishment employment, value of output, location, industry, age, ownership, and so forth. Some details on variables and variable construction are contained in the appendix to this paper. The establishment-level survey data in both the PACE

\footnotetext{
${ }^{3}$ See, for example, U.S. Bureau of the Census (1994). These publications also contain sample survey forms.

${ }^{4}$ Unfortunately, the establishment-level data from 1973-1978 and 1983 are no longer available. A survey for reference year 1987 was not conducted.
} 
and ASM are confidential, collected and protected under Title 13 of the U.S. Code.

After restricting my attention to cases that were in both the PACE and ASM samples in a given year, and after eliminating survey non-respondents, certain item non-respondents, nonmanufacturing establishments, inactive cases, and so forth, I am left with 89,889 plant-years of observations for my empirical analyses. (See appendix for details on sample selection.) There are 28,831 unique establishments in this sample, in 2,260 unique counties. The median establishment here appears in 3 of the 8 years; the mode is just one appearance. Table 1 shows the distribution of the sample by year and by 2-digit SIC category.

Table 2 contains some basic sample statistics on air pollution abatement (henceforth, "APA") outlays. Amounts are in constant 1988 dollars, indexed using the U.S. Bureau of Economic Analysis's implicit price deflator (Survey of Current Business, August 2001). We see here that there is about $\$ 13.3$ billion of APA capital expenditure in this sample, accounting for $3.3 \%$ of total capital expenditures for these plants. The average establishment in this sample has about $\$ 148,000$ of APA capital expenditure a year. Expenditures are higher in terms of APA operating costs, with about $\$ 28.5$ billion worth in this sample, for an average of about $\$ 317,000$ per plant per year. As a fraction of total outlays, however, APA only accounts for $0.4 \%$ of total operating costs for these plants.

It is important to note that the distributions of APA expenditures are quite skewed. Of the 89,889 observations in the sample, only $22.9 \%$ actually have positive APA capital expenditure. This might be expected since capital investment is (by its very nature) lumpy, and not all manufacturing activity is polluting, requiring the installation of special equipment. The average APA capital expenditure per plant, given that it is positive, is $\$ 646,000$. Similarly, only $46.5 \%$ of observations have positive APA operating costs, and the average APA operating costs per plant per year, given that it is positive, is nearly \$682,000. In 2000 dollars, these amounts are about $\$ 862,000$ and $\$ 910,000$, respectively.

Since the majority of observations here have zero expenditures, I take two approaches to estimation: (1) a probit model for having positive expenditures, and (2) a Tobit specification. The general estimating equation will be the same for both:

\footnotetext{
${ }^{5}$ Restricted access to these data can be arranged through the Census Bureau's Center for Economic Studies. See http://www.ces.census.gov/ for details.

${ }^{6}$ Since larger establishments are sampled more heavily in the PACE and ASM surveys, these figures are not representative of the typical manufacturing establishment.
} 


$$
A P A_{i t}=\alpha+\delta_{t}+\phi_{s}+\beta^{\prime} X_{i t}+\pi^{\prime} E_{n}+\lambda^{\prime} K_{c}+\theta^{\prime} N_{c t}+\psi^{\prime} Z_{n c t}+\varepsilon_{i t}
$$

where $i$ indexes an establishment that is in county $c$, state $s$, and industry $n$, and $t$ indexes time. Here, the dependent variable (APA capital expenditure or APA operating costs) is a function of a constant, a year effect, and a state effect, as well as vectors of establishment characteristics, emission characteristics of the plant (based on its 4-digit industry), some time-invariant county characteristics, the county's non-attainment statuses vis-à-vis the various criteria air pollutants, and indicators of whether the plant is subject to heightened "local" regulation - namely, whether it is a high emitter of any of the criteria pollutants in a county that is in non-attainment of the NAAQS for the respective pollutant(s). ${ }^{\square} \mathcal{E}_{i t}$ is an error term. Richer, alternative models will be considered below.

The establishment characteristics $\left(X_{i t}\right)$ I control for here are plant size (as measured by total employment), the age of the plant, and whether or not it belongs to a multi-unit firm. These three factors have been shown to be important determinants of who gets regulated when and how intensely, at least in terms of air quality regulation (Becker 1998, Becker and Henderson 2000). In particular, all else being equal, larger facilities appear to be scrutinized first and most intensely. In a world of limited regulatory resources and a fixed cost incurred with each establishment investigated, this can be an efficient strategy (see Pashigian (1984) for a discussion).

Plants belonging to multi-unit firms, besides being larger on average, may also be inherently more sensitive to environmental concerns, since these firms may have that much more to lose (in terms of corporate assets, reputation, and so forth) if found to be environmentally negligent. Their greater visibility may also make these establishments attractive targets for regulators wanting to send signals to other firms in the area (and to the public), much more so than relatively small, independent, locally-based, entrepreneur-run firms, which may be politically unpopular targets in their own right. Finally, because environmental regulations often distinguish between new and existing plants, age is included here as another factor potentially affecting APA expenditures.

Given these establishment characteristics, air pollution abatement expenditure is also no

\footnotetext{
${ }^{7}$ This regulation is "local" in the sense that it arises from local circumstances, specifically NAAQS non-attainment, is limited to certain areas, and is in addition to whatever state and federal standards may be in place. The regulation, however, is in fact a product of the Clean Air Act, and may in fact be designed and enforced by state regulators or even by the EPA itself in certain instances. Nonetheless, the convention of referring to this type of regulation as local will be used throughout the paper.
} 
doubt related to the emissions generated by a plant, with heavier polluters subject to greater federal, state, and local regulation. I classify establishments as (potential) heavy emitters of the criteria air pollutants according to their 4-digit Standard Industrial Classification (SIC) code. ${ }^{{ }_{I}}$ categorize industries as heavy emitters based on the EPA's Aerometric Information Retrieval System (AIRS) which, among other things, maintains an inventory of facilities in the United States (classified by industry) that emit a threshold amount of any of the six criteria air pollutants. 9

For each pollutant, I obtained the number of establishments in each 4-digit SIC emitting over the threshold amount set by the EPA. ${ }^{10}$ I then label an industry - and all its plants - a "high emitter" of that air pollutant if it had a minimum number of establishments emitting above that threshold. ${ }^{11}$ The assumption here is that the presence of the industry in the right tail of the facility emissions distribution says something about the emissions of the typical plant in the industry. (This classification scheme is validated by the empirical results in the next section.) The resulting indicator variables are vector $E_{n}$ in equation (1). Table 3 shows the number and percent of the 449 manufacturing industries, and the number and percent of the 89,889 sample observations, defined as high emitters of each of the six criteria pollutants. (See appendix for more details on the AIRS database and the designation of high emitters.)

Beyond plant and industry characteristics, certain community characteristics may affect the intensity of local regulation and, in turn, establishments' air pollution abatement expenditures. Table 4 describes the county-level variables (apart from air pollutant non-attainment statuses) that I control for here in this study. The local characteristics these variables attempt to capture are, for the most part, ones that are unlikely to have changed very much, or in important ways, during the time period under study here; they are therefore treated as time-invariant $\left(K_{c}\right.$ in

\footnotetext{
${ }^{8}$ Previous studies have defined polluters by their 2-digit industry (e.g., Levinson 1996, List and McHone 2000, Greenstone 2001) or according to their 4-digit industry's (relative) environmental expenditures in the PACE survey (e.g., Pashigian 1984, Gray 1997). The former is much too crude, and the latter is obviously inappropriate here since I'm trying to explain PACE expenditures in this study.

${ }^{9}$ Note that, throughout, I wish "emissions" to mean "total air pollution generated." The emissions data in the AIRS, however, are in fact "releases into the atmosphere" (i.e., total emissions less emissions abated). The two are likely highly correlated.

${ }^{10}$ For VOC, $\mathrm{NO}_{2}, \mathrm{SO}_{2}$, and particulates, the threshold is 100 tons per year. For $\mathrm{CO}$, the threshold is 1000 tons per year. For lead, it is 5 tons per year.

${ }^{11}$ For CO, particulates, and lead, industries with 1 or more establishments above the (respective) threshold are considered high emitters. For $\mathrm{NO}_{2}$ and $\mathrm{SO}_{2}$, industries with 2 or more establishments above the threshold are considered high emitters. For VOC, industries with 4 or more establishments above the threshold are considered high emitters. These particular cutoffs were chosen so that no more than $50 \%$ of the establishments in this sample are designated a high emitter of any pollutant.
} 
equation (1)). $\frac{12}{12}$ Unless noted otherwise, the county data are based on the 1980 Census of Population and Housing and were extracted from the Census Bureau's USA Counties 1998 (CDROM).

Some local constituencies may demand that their regulators adopt policies more stringent than required by the CAA. A higher density of population surrounding a plant, for example, may increase the pressure placed on it since its emissions (left unabated) adversely affects that many more people (Kahn 1999). Homeowners in particular may demand greater pollution abatement efforts from their nearby plants; numerous studies have demonstrated a relationship between ambient air quality and property values (see Chay and Greenstone (2000) for a recent examination). Other groups, however, may be more hostile to additional environmental protection. The unemployed and those engaged in manufacturing, in particular, may feel their very livelihoods threatened by increased regulation (Gray and Deily 1996, Kahn 1999).

Apart from these potential political factors, the demand for environmental quality, like that for any other good, may simply derive from income and preferences. If environmental protection is indeed a normal good (e.g., Kahn and Matsusaka 1997), wealthier counties might be expected to press for stricter requirements on their polluting plants. Demand might also be expected to depend on one's vulnerability to air pollution, and the EPA has identified children and the elderly among those particularly at risk. I further proxy for a county's "taste for health" by observing the number of active physicians per capita. Finally, I allow educational attainment and political ideology to also shape a county's preference for environmental protection. Kahn and Matsusaka (1997) have a particularly nice discussion of the role these variables may play in determining environmental outcomes.

Local characteristics may also explain the "supply" of environmental protection. Much has been written on the issue of "environmental injustice" (a.k.a. environmental inequity, racism, discrimination, etc.) - the notion that polluting facilities are more likely to be situated near minority communities and/or toxic emissions are higher in such areas (see Arora and Cason

\footnotetext{
${ }^{12}$ Since county non-attainment status vis-à-vis the different criteria air pollutants does vary over time (see below), this then raises the obvious question: Why not simply employ county fixed effects in my empirical specification, rather than these "time-invariant" county-level control variables? The dilemma is that, during this time period and in this sample, counties' non-attainment statuses do not vary very much. In the best case, with county fixed effects, just $16.5 \%$ of the observations in the sample (in 272 unique counties) would help identify the effect of ozone nonattainment status. In the worst case, only $5.7 \%$ of observations (in 47 unique counties) would contribute to the identification of $\mathrm{CO}$ non-attainment effects. The practicality of estimating models with some two thousand county fixed effects is also an issue.
} 
(1999) and Hite (2000) for recent examples). Here, I allow for the possibility of such discrimination on the part of firms (and obviously, by extension, regulators) by controlling for the nonwhite proportion of a county's population and the percent that is foreign-born. Unequal regulatory treatment (and pollution abatement expenditure) may also be due to disparate caseloads among local regulators. One might expect, for example, all else being equal, that a plant in a region with more polluters may face a lower probability of being inspected and perceive a greater opportunity to shirk environmental obligations. A measure of "polluters" per capita is meant, in part, to capture this effect.

As described in the preceding section, a key determinant of air quality regulation under the CAA is a county's non-attainment statuses vis-à-vis the criteria air pollutants $\left(N_{c t}\right)$. Beginning in 1978 , every county in the United States is officially designated every year as being either in attainment or non-attainment of the NAAQS for each of the six pollutants. This information is released each July in the Code of Federal Regulations (Title 40, Part 81, Subpart C). For this study, an establishment is deemed to have been in a county with more stringent regulation vis-àvis a particular pollutant, if the county was classified in non-attainment of the NAAQS for that pollutant in the prior calendar year (i.e., the July 1978 designation affects APA expenditures in 1979, and so forth). Counties in violation of the "secondary" NAAQS standard (for $\mathrm{SO}_{2}$ and TSP), or where only portions of the county were out of compliance, are also considered to have been in non-attainment for the purposes of this study. (See the appendix for further discussion.)

The number and percent of observations in this sample, therefore, located in ozone $\left(\mathrm{O}_{3}\right)$, particulate (TSP), carbon monoxide (CO), and sulfur dioxide $\left(\mathrm{SO}_{2}\right)$ non-attainment counties are $61.7 \%, 50.7 \%, 36.7 \%$, and $9.8 \%$, respectively. 3 Counties can, of course, be in non-attainment of the NAAQS for more than one criteria pollutant at the same time. In this sample, for example, $52.3 \%$ of the establishments were in a county in violation of multiple NAAQS.

At last, we have the primary explanatory variables of interest in this study - the indicators

\footnotetext{
${ }^{13}$ County non-attainment status vis-à-vis the other two criteria pollutants - airborne lead $(\mathrm{Pb})$ and nitrogen dioxide $\left(\mathrm{NO}_{2}\right)$ - will not be considered in my empirical analyses. During the time period studied here, county lead nonattainment status was not listed in the Code of Federal Regulations along with the other criteria pollutants, and I was otherwise unable to locate this information. It is very likely that relatively few counties were actually in lead nonattainment during this time; in August 2001, only (portions of) four U.S. counties were in lead non-attainment. I ignore county $\mathrm{NO}_{2}$ non-attainment status here (a) because during the time period being studied, no more than a dozen counties were ever in $\mathrm{NO}_{2}$ non-attainment and (b) since ground-level ozone $\left(\mathrm{O}_{3}\right)$ forms through the interaction of both $\mathrm{NO}_{2}$ and $\mathrm{VOC}$ emissions, ozone non-attainment status is actually relevant to high emitters of both pollutants (and is treated as such in my empirical analyses). Incidentally, these dozen $\mathrm{NO}_{2}$ non-attainment counties were also always in ozone non-attainment at the same time.
} 
in vector $Z_{n c t}$ of equation (1) - whose coefficients $(\psi)$ capture effects of additional local regulation necessitated by the requirements of the Clean Air Act. The additional regulatory costs are identified here by comparing establishments that are and aren't in non-attainment counties, in industries that are and aren't heavy emitters of the targeted pollutant(s). So, for example, all else being equal, are APA expenditures indeed higher for high $\mathrm{SO}_{2}$ emitters in $\mathrm{SO}_{2}$ non-attainment counties, relative to $\mathrm{SO}_{2}$ emitters in $\mathrm{SO}_{2}$ attainment counties and low-to-no $\mathrm{SO}_{2}$ emitters regardless of county?

The dummy variables used to indicate whether a plant is indeed subject to heightened local regulation come from the Kronecker product of the vectors $E_{n}$ and $N_{c t}$ :

$$
Z_{n c t}=E_{n} \otimes N_{c t}
$$

Five effects are of key interest here, in particular, the effects of $\mathrm{O}_{3}$ non-attainment on high VOC and high $\mathrm{NO}_{2}$ emitters, TSP non-attainment on high PT emitters, $\mathrm{CO}$ non-attainment on high $\mathrm{CO}$ emitters, and $\mathrm{SO}_{2}$ non-attainment on high $\mathrm{SO}_{2}$ emitters. The fifteen "cross-effects" (i.e., the effect of TSP non-attainment on high VOC emitters, and so forth) are not meaningful in and of themselves, and their inclusion in empirical specifications is found to introduce substantial multicollinearity. They are, therefore, not featured in the empirical work below.

Table 5 shows the number and percent of establishments in this sample under more stringent (pollution-specific) local regulation as a result of the Clean Air Act. At the extremes, just over $4 \%$ of plants in this sample are high $\mathrm{SO}_{2}$ emitters in a county designated as being in $\mathrm{SO}_{2}$ non-attainment, while $30.3 \%$ are high VOC emitters in $\mathrm{O}_{3}$ non-attainment counties. Locally regulated $\mathrm{NO}_{2}$ and PT emitters also have a considerable presence here $(25.3 \%$ and $21.1 \%$, respectively), while more heavily regulated $\mathrm{CO}$ emitters are relatively scarce $(5.7 \%)$.

Establishments can, of course, fall into more than one of these categories. Overall, $44.2 \%$ of the establishments in this sample faced heightened local regulation for at least one of these five pollutants. The next section will explore whether APA capital expenditures and APA operating

\footnotetext{
${ }^{14}$ A potential consequence of their exclusion from empirical models may be illustrated with the hypothetical case of a high $\mathrm{SO}_{2}$ / high TSP emitter located in an $\mathrm{SO}_{2}$ non-attainment county. Though this establishment may only be required to reduce its $\mathrm{SO}_{2}$ emissions, it may decide to abate its (high) TSP emissions as well — perhaps because the technology is such that the additional cost of doing so is low and/or it anticipates that it may be regulated for TSP in the future (and chooses to incur the fixed costs associated with installing pollution abatement equipment just once). This would result in the "misattribution" of those additional TSP-related costs to the effect of $\mathrm{SO}_{2}$ non-attainment on $\mathrm{SO}_{2}$-related abatement. These costs, however, if they indeed exist, are presumably of a secondary order of magnitude. If this is the case, the coefficients on the five principal variables of $Z_{n c t}$ may be viewed as capturing the primary as well as any "secondary" effects of CAA-related regulation on high emitters of criteria air pollutants.
} 
costs are indeed higher for these more heavily regulated plants, as is expected.

\section{RESULTS}

\section{Baseline model}

Tables 6 and 7 contain regression results on APA capital expenditures and APA operating costs, respectively, for the model specified in equation (1). The first column of each table contains estimates from a probit model for having positive expenditures. Note the predicted probability of positive APA capital expenditure and operating costs, evaluated at the variable means, is $19.6 \%$ and $47.2 \%$, respectively, compared to observed probabilities of $22.9 \%$ and $46.5 \%$ (seen in Table 2). The estimates in this column reflect the change in probability for discrete changes in the dummy variables and infinitesimal changes in the continuous variables. Robust (i.e., Huber/White/sandwich) standard errors are in parentheses. The second column of each table contains estimates from a Tobit model on real expenditures. The units here are in thousands of 1988 dollars. Throughout, statistical significance at the 5\% [10\%] level is indicated by double [single] asterisks.

Both the probit and Tobit models control for a constant plus year and state effects, none of which are reported here. Year effects capture national trends in air pollution abatement activity as well as any year-to-year idiosyncrasies in the sample. State effects recognize that there may be important state-level differences in regulatory stringency (Gray 1997, Levinson 2001); they also absorb some (potential) spatial variation in factor prices. A less restrictive specification with state-by-year effects (i.e., $\varphi_{s t}$ in equation (1), rather than $\delta_{t}+\phi_{s}$ ) has also been estimated, with little (statistical) impact on the main coefficients of interest. Specifications that include industry effects, as well as some interaction terms, will be considered later in this paper.

Results here show that establishment characteristics matter. Plant size, as measured by establishment employment, had a significant (non-linear) effect on the probability and level of both types of APA outlays, with increasing probabilities and expenditures throughout nearly the entire distribution of plant employment. Establishments belonging to multi-unit firms also had higher probabilities of positive APA expenditures, with increases of 10.7 and 19.7 percentage points, according to the probit estimates. The Tobit results show that the average multi-unit establishment had APA capital expenditures and operating costs that were \$1.3 million and \$1.4 million greater, respectively, compared to otherwise similar single unit plants. 
Establishment age also matters significantly. Relative to the youngest plants (the omitted group), older plants were more likely to have had positive expenditures and, all else being equal, had much higher APA capital and operating costs, with point estimates that increase (almost) monotonically with successively older generations. The oldest category of plants (4+ "generations" or at least 16 years old) had additional likelihoods of 8.1 and 14.6 percentage points, respectively, and additional expenditures of about $\$ 0.9$ million and $\$ 1.0$ million, respectively.

None of these results, however, necessarily speak to hypotheses of the regulatory implications of establishment characteristics, as explored by Becker and Henderson (2000, 2001), Dean et al. (2000), among others. The relevant testable models, in this context, would include interaction terms between these plant characteristics and the regulatory variables (i.e., $X_{i t}$ $\left.\otimes Z_{n c t}\right)$. This will be explored later in the paper.

The results on the county characteristics are rather mixed. ${ }^{5}$ Population density is generally found to have had a negative effect on the probability and level of APA expenditures, contrary to what was hypothesized. Increased homeownership, on the other hand, generally raised air pollution abatement activity, as expected, particularly once a critical mass (of about 60\%) was reached. County unemployment does not seem to have impacted APA outlays. The percent of the labor force engaged in manufacturing, however, has a statistically significant impact in all four specifications; the relationships estimated, though, are inconsistent with what was expected.

County per capita income also has a statistically significant impact in all specifications. The probit estimates indicate that the probabilities of having had positive APA expenditures rose through to about the median of the distribution of county income (for this sample of plants) and then fell, such that there was little difference between plants in the 10th vs. 90th percentile, 25 th vs. 75th percentile, etc. The Tobit results, on the other hand, show APA expenditures (generally) increasing with county income - consistent with the notion that environmental protection is indeed a normal good. In terms of APA operating costs [capital expenditures], establishments at the median of the per capita income distribution in this sample had expenditures that were $\$ 348,200[\$ 218,700]$ higher, on average, than those at the 10th percentile, and those at the 90th percentile had outlays that were $\$ 477,100$ [\$212,500] greater, all else being equal.

\footnotetext{
${ }^{15}$ What may be of particular interest is the separate effect of these local characteristics on the air pollution abatement activities of high criteria air pollutant emitters. Such analyses, however, are beyond the scope of this current paper.
} 
In terms of the other "demand-side" variables, the proportion of a county's population particularly sensitive to air pollution (i.e., the young and old) appears to have had a negative effect on the probabilities of positive APA expenditures but no effect on the actual levels that expenditure. Meanwhile, the educational attainment of a populace is found to have had an unexpected negative effect on APA operating costs but no effect on capital expenditures. An increased presence of doctors, with one exception, had no effect on APA activity, while an increase in Democratic voters (traditionally thought to favor environmental causes) had a positive effect on the propensity of having had both types of expenditures but no discernible effect on the average level of those expenditures.

In terms of the "supply" of environmental protection, there is scant evidence of environmental inequality here. ${ }^{16}$ All else being equal, establishments spent no more or no less on air pollution abatement in counties with larger nonwhite populations. And while the share of the population that is foreign-born is generally found to have statistically significant effects, only in one case do they suggest "environmental injustice" (on the decreased likelihood of APA capital investment).

The per capita number of polluters in a county, however, does indeed play a role in explaining plant-level air pollution abatement expenditures, with average APA activity decreasing, as expected, as the number of polluters local regulators must oversee increases. All else being equal, for example, establishments in counties with just 54 polluters per 100,000 population (the 10th percentile in this sample), had APA capital expenditures [operating costs] that were about $\$ 328,900[\$ 533,300]$ higher than similar plants at the 90th percentile (with 135 polluters per 100,000) and a likelihood of having had such expenditure that was roughly 2.5 [6.4] percentage points higher. These differences may suggest an inappropriate distribution of regulatory resources across jurisdictions, or perhaps we are seeing the burden of achieving the same environmental goals shouldered by more versus fewer parties.

Turning to the emission characteristics of establishments, they are, not surprisingly, significant determinants of air pollution abatement expenditure. With little exception, potential heavy emitters of the criteria pollutants had both higher likelihoods and higher levels of APA outlays in terms of both capital expenditures and operating costs. This reflects greater state and federal regulation of these types of emission sources, relative to plants in less-polluting industries

\footnotetext{
${ }^{16}$ Of course the aforementioned income effect might (also) suggest discrimination against low-income groups.
} 
(and regardless of their actual location). Among the minimum requirements on large emitters during this time period were various New Source Performance Standards (NSPS), the Prevention of Significant Deterioration (PSD) in attainment areas, and (in the later years) Toxics Release Inventory (TRI) reporting, mandated by the Emergency Planning and Community Right-toKnow Act (EPCRA) of 1986. To some extent, the higher spending seen here may also represent voluntary adoption of air pollution control technologies by polluting industries. In any event, I believe these findings validate my particular classification of "high emitters."

In terms of actual results, Table 6 shows that the added probability of positive APA capital expenditures for high emitters ranged from 4.0 to 12.7 percentage points, for high VOC and $\mathrm{CO}$ emitters, respectively, while dollars of additional capital expenditure averaged $\$ 343,500$ for high VOC emitters, \$456,200 for high $\mathrm{SO}_{2}$ emitters, \$802,500 for high PT emitters, and nearly $\$ 1.4$ million for high CO emitters. In terms of APA operating costs, likelihoods ranged from 4.1 to 17.6 percentage points higher, for high emitters of $\mathrm{NO}_{2}$ and $\mathrm{CO}$, respectively, and additional costs ranged from $\$ 205,700$ for high VOC emitters, $\$ 637,300$ for high $\mathrm{SO}_{2}$ emitters, $\$ 847,800$ for high PT emitters, to nearly $\$ 1.6$ million for high CO emitters. $\frac{7}{7}$ Alternatively, $\mathrm{NO}_{2}$ emitters are not found to have had higher APA expenditures, ceteris paribus, which may be indicative of the fact that very few counties were actually in $\mathrm{NO}_{2}$ non-attainment during this period — the regulation of $\mathrm{NO}_{2}$ sources in general may have been a relatively low priority nationwide.

A county's non-attainment statuses, one might expect, should only impact a plant's APA activity in the event that the establishment is a high emitter of a pollutant and its county is in violation of the NAAQS for that pollutant. However, we see that non-attainment status, per se, does matter in a number of cases. In particular, county $\mathrm{O}_{3}$ non-attainment appears to have raised the probability (but not the amount) of APA capital expenditures and operating costs, while county $\mathrm{CO}$ and $\mathrm{SO}_{2}$ non-attainment appear to have lowered APA outlays. This suggests, perhaps, the existence of omitted variables in my empirical analyses.

In the case of $\mathrm{O}_{3}$, perhaps NAAQS non-attainment - which may in fact be a well-known event given the prevalence and conspicuousness of summertime "ozone alert" days - raises air quality awareness in the general populace, who in turn pressure regulators to require more of

\footnotetext{
${ }^{17}$ While it may seem that high CO emitters were particularly affected by regulation, cross-pollutant comparisons such as this are somewhat capricious. Given the variation in toxicity across pollutants, the thresholds set by the EPA for inclusion in the AIRS database, and the criteria used here to define high emitters, the equivalence of high emitters of the different air pollutants is, at best, indefinite. We should not, therefore, necessarily expect the magnitude of these effects to be the same.
} 
local manufacturing plants regardless of their actual emissions. For $\mathrm{CO}$ and $\mathrm{SO}_{2}$ non-attainment counties, a different story is likely, considering how different these two pollutants are from the other criteria air pollutants.

Both $\mathrm{CO}$ and $\mathrm{SO}_{2}$ have significant sources outside of manufacturing (and therefore outside the scope of the PACE survey and this current study). In the case of CO, EPA (2000) estimates that in 1998, 78.6\% of emissions were generated by transportation (mainly motor vehicles), while just $5.4 \%$ originated from industrial processes. It may be the case, therefore, that counties in $\mathrm{CO}$ non-attainment, on the whole, divert (already scarce) resources away from the regulation of industrial sources - resulting in the lower overall APA activity observed here - toward the regulation and management of mobile sources (e.g., through vehicle emission inspection and control programs, public transportation initiatives, $\mathrm{HOV}$ infrastructure, and so forth). With $\mathrm{SO}_{2}$, $85.1 \%$ of emissions came from fuel combustion (mainly at electric utilities), versus just $7.7 \%$ from industrial processes. Here again, affected counties may be diverting their regulatory attention away from the manufacturing sector, in general, toward power-generating plants in particular. The result is a "savings" for manufacturing establishments.

The final set of coefficients in these tables are the ones of primary interest in this study. Controlling for establishment characteristics, including potential emissions, county characteristics, including non-attainment statuses, as well as state and year effects, did manufacturing plants with high emissions, located in counties that were in non-attainment of the NAAQS for the respective pollutant(s), indeed have higher air pollution abatement expenditure? Compliance with the Clean Air Act, after all, would have presumably subjected these establishments to more stringent local standards, at least on average.

Table 6 shows that high VOC emitters in $\mathrm{O}_{3}$ non-attainment areas were actually less likely to have had positive APA capital expenditure, all else being equal, but the Tobit results show that the effect in dollar terms is (statistically) zero. Ozone non-attainment status is also found to have had no effect on the other important precursor to tropospheric ozone, high $\mathrm{NO}_{2}$ emitters, but for high emitters of the other pollutants, greater local regulation is evident. High PT emitters in TSP non-attainment counties had an additional likelihood of 2.4 percentage points of having positive APA capital expenditure and had, all else being equal, \$170,900 more capital expenditure, relative to high PT emitters in TSP attainment areas and low-to-no TSP emitters (regardless of their location). High $\mathrm{CO}$ emitters in $\mathrm{CO}$ non-attainment areas were not more likely to have had 
APA capital expenditures but, on average, had $\$ 285,000$ more such expenditure. And high $\mathrm{SO}_{2}$ emitters in $\mathrm{SO}_{2}$ non-attainment counties had an additional likelihood of 2.3 percentage points and had APA capital expenditure that was $\$ 432,600$ higher than for similar plants in $\mathrm{SO}_{2}$ attainment areas and non- $\mathrm{SO}_{2}$ emitters. All results are statistically significant at (at least) the $5 \%$ level.

In terms of additional APA operating costs (Table 7), high VOC emitters in $\mathrm{O}_{3}$ nonattainment areas were, again, less likely to have had positive expenditures, however they did have $\$ 179,100$ in higher costs, on average, than plants that did not face local regulation of VOC emissions. And, as was the case with capital expenditures, ozone non-attainment status had no significant effect on the outlays of high $\mathrm{NO}_{2}$ emitters. 8 High PT emitters in TSP non-attainment counties, however, had both higher likelihoods (by 5.0 percentage points) and higher levels $(+\$ 260,300)$ of APA operating costs, compared to other plants, as did high $\mathrm{SO}_{2}$ emitters in $\mathrm{SO}_{2}$ non-attainment areas, who had probabilities that were 2.9 percentage points greater and costs that were \$517,900 higher. High CO emitters in CO non-attainment areas were less likely to have air pollution abatement operating costs (by 2.3 percentage points) but, on average, had $\$ 241,400$ more such expenditure (though this is more than offset by the aforementioned "savings").

In summary, three of these five categories of establishments, under heightened local regulation, had higher air pollution abatement capital expenditure, and four of the five had higher APA operating costs. These additional costs each ranged in the hundreds of thousands of (1988) dollars, and an establishment obviously may have incurred both types of outlays, possibly for multiple air pollutants.

The results from the probit regressions are more mixed. Four of the ten estimates indicate a greater likelihood of having had positive expenditures, while three estimates indicate a lower propensity. The notion that the effects of an explanatory variable on the probability of expenditure versus the level of expenditure can be independent (and even opposite) of one another is certainly not new (e.g., Cragg 1971). And perhaps it should not be surprising in this context, since the goal here of regulators is not pollution abatement expenditure per se, but rather reducing collective emissions in (presumably) a cost-effective manner. A choice can obviously be made between regulating more sources or fewer sources more intensively. This relates back to earlier comments regarding efficient use of regulatory resources.

\footnotetext{
${ }^{18}$ Again, very few counties were actually in $\mathrm{NO}_{2}$ non-attainment during this time period, and it is possible that the control of tropospheric ozone focused primarily on VOC emissions.
} 
Table 8 summarizes some of the key effects air quality regulation had on the level of air pollution abatement expenditure in these manufacturing establishments, using (only) the statistically significant point estimates from the Tobits in Tables 6 and 7. Here, the additional regulatory costs for high emitters in non-attainment counties are calculated relative to the costs for low emitters in attainment areas. The table also shows the proportion of these plants' APA outlays attributable to state and federal regulation (i.e., the $\pi$ coefficients) as well as the relative import of these costs with respect to these plants' total expenditures (on environmental and nonenvironmental matters).

We see here that, without exception, most of the additional cost faced by heavy polluters in non-attainment counties resulted from stricter state and federal standards on these types of sources rather than greater local regulation (due to county non-attainment status). And while air quality regulation in general increased establishments' annual operating costs more than it did their capital expenditures $(+\$ 384,800$ vs. $+\$ 343,500 ;+\$ 1,108,100$ vs. $+\$ 973,400$; etc. $)$, relative to the total outlays of each type, the impact was much greater on these plants' capital expenditures. In particular, the regulation of a single air pollutant never explains more than $1 \%$ of the average regulated plant's operating costs, while 5-14\% of its annual capital expenditures can be explained by such regulation. Table 2 had suggested the existence of such differences.

\section{Model with industry effects}

An alternative model to the one just presented would replace $\pi^{\prime} E_{n}$ in equation (1) with pure industry effects $\left(\mu_{n}\right)$. This does two things. First, it allows for greater heterogeneity in the regulatory treatment of industries at the state and federal level (by allowing some 450 unique effects rather than just five). Second, it mitigates a potential bias from a potential non-random sorting of plants and industries across counties (and attainment and non-attainment areas in particular). For instance, suppose a county is in TSP non-attainment not because it has more than its fair share of high PT emitters (as defined here), but because its high PT emitters tend to be in industries with particularly high PT emissions - much higher than the "average" high PT emitter and (not coincidentally) much higher than the high PT emitters in TSP attainment areas. To the extent that these industries also happened to be subject to greater state and federal regulation, the previous $\psi$ coefficients may reflect more than just the effects of local regulation.

Regression results from such a model with 4-digit SIC industry effects are contained in 
Tables 9 and 10. In the interest of space, only the coefficients on the five indicators of local regulation are presented here. These tables therefore are comparable to the last panels of Tables 6 and 7, respectively. Note that there are somewhat fewer observations in the probit regressions here since some industry effects perfectly predict the expenditure outcomes of plants in those industries.

We see that, after controlling for industry, the significant negative effects found in the earlier probits (with respect to local regulation) have all disappeared, as have some of the previous positive coefficients. The only statistically significant effects now found are the impact of TSP non-attainment status on the capital expenditure of high PT emitters (an increased likelihood of positive expenditure of 1.2 percentage points, down from 2.4), the effect of $\mathrm{SO}_{2}$ non-attainment on the capital expenditure of high $\mathrm{SO}_{2}$ emitters (an increased likelihood of positive expenditure of 1.7 percentage points, down from 2.3), and the effect of CO nonattainment on the capital expenditure of high CO emitters (an increased probability of 1.6 percentage points, previously 0.5 and statistically insignificant). None of the indicators of greater local regulation have any impact on the probability of positive APA operating costs.

In terms of their effects on the levels of expenditure, most but not all of the previous results are sustained. The notable exception is that the impact of TSP non-attainment on both the capital expenditure and operating costs of high PT emitters disappears once industry effects are controlled for. This suggests that the above bias may have indeed been present. There is also one new result here: $\mathrm{O}_{3}$ non-attainment is now found to have also raised the APA operating costs of high $\mathrm{NO}_{2}$ emitters, by $\$ 123,700$ on average, to go along with the impact it is shown to have had on the operating costs of high VOC emitters (which is now at \$288,000). CO nonattainment status is still found to have affected both the capital expenditure and operating costs of high CO emitters, with slightly higher point estimates in this specification $(\$ 323,800$ and $\$ 287,300$, respectively). And $\mathrm{SO}_{2}$ non-attainment is still shown to have impacted the APA capital expenditure and operating costs of high $\mathrm{SO}_{2}$ emitters, though the point estimates are now substantially lower, at $\$ 315,800$ and $\$ 187,900$, respectively. $\frac{19}{1}$

\footnotetext{
${ }^{19}$ I will note here that multicollinearity among the many county covariates (including non-attainment statuses) does not appear to be a major concern here. The respective Tobit coefficients for locally-regulated $\mathrm{VOC}, \mathrm{NO}_{2}, \mathrm{PT}, \mathrm{CO}$, and $\mathrm{SO}_{2}$ emitters, in a specification that completely excludes the time-invariant county-level variables $\left(K_{c}\right)$, for example, are $\left\langle+111.8,-85.0,+58.7,+302.3^{* *},+295.9^{* * *}\right\rangle$ and $\left\langle+280.5^{* *},+143.4^{* *},+21.0,+257.1^{* *},+161.5^{*}\right\rangle$ for capital expenditures and operating costs, respectively. These estimates are very similar to those in Tables 9 and 10 .
} 
Six of these ten coefficients reveal increased air pollution abatement outlays resulting from CAA-related local regulation, with estimates that are (again) in the hundreds of thousands of dollars. Later, I will discuss some potential reasons for the apparent lack of effects in these other cases. In terms of average state and federal regulation, Table 11 lists the twenty industries with the highest establishment-level air pollution abatement capital expenditures and operating cost, everything else being equal. These rankings are based on the industry effects $\mu_{n}$. Not surprisingly, industries in chemicals, petroleum, primary metals, and nonmetallic minerals figure prominently here. Many of these have been specific targets of NSPS requirements from the earliest days of the Clean Air Act (see 40 CFR Part 60) and/or are among the twenty-eight source categories explicitly codified into the PSD program in 1977 (CAA, §169). Without a doubt, most are significant emitters of multiple criteria air pollutants. The overlap here with a similar classification by Pashigian (1984), incidentally, is considerable.

\section{Impact of establishment characteristics}

Finally, I explore more fully the impact of establishment characteristics on air pollution abatement expenditures. To do so, to the model just presented (with industry effects), I add interaction terms between the plant characteristics and the local regulatory variables (i.e., $X_{i t} \otimes$ $\left.Z_{n c t}\right)$. To simplify the analysis, the regulatory variables are collapsed into a single indicator: whether the establishment is subject to heightened local regulation for at least two of the four main criteria pollutants. (Since $\mathrm{NO}_{2}$ sources were hardly ever regulated because of county $\mathrm{NO}_{2}$ non-attainment, $\mathrm{NO}_{2}$ is excluded here.) The Tobit results from this specification, on both APA capital expenditure and operating costs, are found in Table 12. In the interest of space, only the coefficients on establishment variables are presented here.

Results show that plant size (as measured by employment) matters, for establishments that were subject to additional local regulation (as defined here) and for those that were not. Except in the extreme right tail, costs (quite naturally) increased with establishment size, and plants subject to greater local regulation are found to have had additional costs (as expected) that also

In addition, results are also relatively robust to whether the industry codes from the ASM files are used to classify establishments or those from the PACE files. (See appendix for a discussion of industry coding issues.)

${ }^{20}$ The two lists are not directly comparable since Pashigian used industry-level PACE data, from 1974-1978, on total pollution abatement operating costs (involving air, water, and solid waste), conditional only on industry value added. He also eliminated the not elsewhere classified (n.e.c.) industries. Nonetheless, sixteen of his twenty "highest cost" industries are also found here in Table 11. 
happened to increase with establishment size. ${ }^{21}$ To help illustrate these results, Figure 1 graphs predicted APA capital expenditures and APA operating costs for plants in the industrial organic chemicals industry (SIC 2865-9) — an industry that is a large emitter of multiple criteria air pollutants, has been among the most regulated (also seen in Table 11), and has been the subject of close examination (e.g., Henderson 1996; Becker and Henderson 2000, 2001). Assuming a typical plant in this industry (belonging to a multi-unit firm; 4+ generations old), in 1979, in the "average" county and state with the industry, predicted costs are plotted for establishments in a county that was in non-attainment of multiple NAAQS (and therefore would have strictly regulated plants in this industry) and for those that were not.

We see that plants in this industry not subject to heightened local regulation are predicted to have had no APA capital expenditure (i.e., the latent variable is negative) up to an establishment size of about 470 employees, after which point expenditures rise at a decreasing rate. Those plants that were under additional local regulation are found not to have had additional fixed expenditures (i.e., the coefficient on the regulatory indicator itself is statistically insignificant), rather their additional costs increased with establishment size, after a threshold of about 435 employees. The average old, "multi-unit" plant in this industry in 1979 - with 714 employees - is expected to have had $\$ 431,700$ worth of APA capital expenditure in (multi-) nonattainment counties versus $\$ 343,200$ in low-regulation counties, a difference of $\$ 88,500$ (in 1988 dollars).

The air pollution abatement operating costs of this industry differs from its APA capital expenditures in two main respects. First, it is predicted to be substantially higher. Indeed, even the smallest of plants in this industry are expected to have had APA operating costs in the hundreds of thousands of dollars. Second, the "wedge" between the curves - representing costs directly attributable to heightened local regulation - is much larger here than it is for capital. So, for example, the average establishment is expected to have had about $\$ 1.80$ million of APA operating costs in the more heavily regulated counties versus $\$ 1.36$ million in the less-regulated ones, a difference of $\$ 436,100$, or almost five times the difference found in capital expenditures. 22

\footnotetext{
${ }^{21}$ The +0.105 coefficient in the capital expenditure regression, though, is only significant at the $12 \%$ level. I deem this near enough to traditional levels of statistical significance to use in the exercises that follow.

${ }^{22}$ The relative difference, however, is obviously less dramatic: about $24.2 \%$ of the average plant's APA operating costs is explained by CAA-related local regulation, compared to $20.5 \%$ of its APA capital expenditure.
} 
What sort of results should we have expected to see with respect to establishment size? Dean et al. (2000) argue that, on net, environmental regulations place smaller establishments at a unit cost disadvantage. The results here, however, suggest that a concave cost-size relationship may only be true: (a) for certain types of costs [after all, in the above example, APA capital expenditures are essentially convex], (b) for the most regulated of industries [the vast majority of industries are predicted to have zero costs for at least some portion of their smaller plants], and/or (c) if one aggregates all possible reasons for air pollution abatement expenditures.

This last qualification is of particular importance here, since the regression results show (via positive first- and second-order terms in the interaction between employment and regulation) that, for the specific type of environmental regulation examined here in this study, compliance costs are in fact convex (at least until the extreme right tail on the plant employment distribution). That is to say, larger establishments - not smaller ones - are disproportionately impacted by CAA-related local regulation. Becker (1998) and Becker and Henderson (2000) have in fact found evidence of such enforcement asymmetries with respect to this regulation (particularly during the time period under study here), arguing that limited regulatory resources may necessitate such targeting. These findings further their claims.

In terms of the other establishment characteristics, Table 12 shows that plants belonging to multi-unit firms spent more on air pollution abatement than similar single-unit plants, with such establishments reporting \$951,600 and \$955,800 higher APA capital expenditure and operating costs, respectively, all else being equal. This supports the notion that multi-unit firms, perhaps because they have more to lose (in terms of corporate assets and reputation) if found to be environmentally negligent, are more sensitive to environmental concerns. Or perhaps this is evidence of a desire (on the part of all firms) to appear "green" - a desire that can only be realized by the larger corporations and their "deep pockets." In any event, the motivation for this additional expenditure appears to be entirely voluntary in nature since "multi-unit" plants that were under stricter local regulation did not have significantly higher (or lower) APA outlays than those that were not. If these establishments were in fact targeted more intensely by regulators than single-unit plants, it was because of their much larger size (as suggested by Becker and Henderson 2000), not because they belonged to multi-unit corporations per se.

Finally, we see that establishment age is generally found to have increased air pollution abatement. Relative to the youngest group of plants, establishments that are 16+ years old had 
$\$ 545,900$ and $\$ 637,100$ more APA capital expenditures and operating costs, respectively, all else being equal. As with multi-unit plants, this additional expenditure may reflect greater environmental effort on the part of establishments with more reputation to lose/protect. In what may seem an unexpected result, however, local regulation is found to have had no differential effect on the APA outlays of plants of different ages. This, despite the fact that air quality regulations generally fall hardest on new establishments - particularly in terms of capital requirements - while exempting existing establishments, at least until they undertake some major updates/modifications. Unfortunately, however, the high initial APA capital expenditures expected in new (regulated) plants are likely to occur during the plant's construction phase before it is in operation and, therefore, before it is eligible to be sampled in the PACE survey. These data, therefore, are not fully adequate to examine such age-related issues.

\section{CONCLuSION}

This paper has revealed some of the costs of air quality regulation in the United States. In particular, the capital expenditures and operating costs associated with the air pollution abatement activity of manufacturing plants, from 1979-1988, are examined using establishmentlevel data from the Census Bureau's Pollution Abatement Costs and Expenditures survey. Results show that high emitters of the "criteria" air pollutants (covered under the Clean Air Act) had significantly larger APA costs (and higher probabilities of having had such outlays) than plants in industries with low emissions, reflecting the heightened state and federal standards on such facilities during this time period. Meanwhile, establishments subject to stringent CAArelated "local" regulation - namely, high emitters of an air pollutant in a county designated as being in non-attainment of the NAAQS for that pollutant - are generally found to have had air pollution abatement expenditures that were greater still.

This heightened local regulation (of a particular criteria air pollutant) generally resulted in hundreds of thousands of (1988) dollars worth of additional APA capital expenditures [operating costs] for the average affected plant in this sample, and an establishment obviously may have had additional outlays of both types of costs, possibly for multiple pollutants. The relative impact was greatest on plants' total capital expenditures than on their operating costs (i.e., expenditures on labor, materials, energy, services, depreciation, etc.); furthermore, the effect of local regulation on the probability of having had APA expenditures was (perhaps not surprisingly) less 
definite than that on the average level of that expenditure.

Analyses also revealed that the air pollution abatement costs associated with this local regulation were directly related to the size of the polluting establishment, with expenditures that increased at an increasing rate (for the most part). That this regulation appears to have disproportionately impacted larger establishments corroborates the findings of certain previous studies (e.g., Becker and Henderson 2000). A plant's corporate structure and age also seem to matter, but not in ways that are related to local regulation, suggesting perhaps the voluntary adoption of pollution abatement technologies by establishments with substantial assets and reputation to protect.

Local regulation (due to county NAAQS non-attainment status) is not the only story here. In fact, it appears that most of the additional costs faced by heavy polluters in non-attainment counties appears to have been due to stricter state and federal standards (e.g., the Clean Air Act's New Source Performance Standards) rather than greater local requirements, and industries in chemicals, petroleum, primary metals, and nonmetallic minerals (not surprisingly) are among those found to have had the highest establishment-level air pollution abatement expenditures attributable to such policies.

Nonetheless, costs associated with local air quality regulation remain of keen interest. First, it is these costs that implicitly underlie the findings of a number of recent studies, including Henderson (1996), Kahn (1997), Becker and Henderson (2000), and Greenstone (2001), which have all documented significant impacts of county non-attainment status on local manufacturing activity, including plant location, employment, investment, and survival. While significant local regulatory costs were apparent in all these studies, they were never directly observed.

Estimates of these additional expenditures are of more than mere academic interest, however. The persuasive case has been made, during recent policy debates, for allowing the EPA to consider the costs of complying with the national ambient air quality standards it sets, in addition to their health benefits. While such cost-benefit balancing is routinely required for many other types of federal regulation, until the Congress revises the Clean Air Act, the Supreme Court has ruled that the EPA is barred from relying on such analyses when setting the NAAQS standards that all locales are required to meet.

It is important to note that these estimates of the costs of air quality regulation are likely lower bounds on the true costs to manufacturing establishments. We in fact see a few instances 
where heightened local regulation had no apparent effect. ${ }_{3}^{3}$ There are a number of reasons for why this might be the case.

First, there are obviously some costs that the PACE survey makes no attempt to capture. For example, establishments during this time period were not asked about potential regulatory expenses such as taxes, fines, permits, pollution offsets, and so forth. Nor do we observe output that may have been lost due to plant shutdowns/slowdowns (to install pollution abatement equipment) or from production efficiency sacrificed in the name of environmental protection. And as mentioned earlier, nascent establishments - with their relatively high expected pollution abatement capital investment - are not covered by the PACE survey at all.

Furthermore, it is possible that the PACE survey misses some portion of costs (Jaffe et al. 1995, Gray and Shadbegian 1995, Becker and Henderson 2001). That is, there may be something inherent in the technologies and techniques used to abate these particular pollutants that make their costs especially difficult to quantify. Capital expenditures of the end-of-line variety, for example, may be relatively easy to identify and measure, but those associated with changes-in-production-processes have long been recognized as difficult to account for, and capturing the various types of operating costs may be equally problematic. (See Becker and Henderson 2001 for a discussion.) Moreover, establishments generally do not keep special track of their outlays on environmental protection; they must therefore estimate such expenditures, sometimes a year or more after they have actually occurred. Since more-regulated plants are more likely to have had these difficult-to-estimate costs, they may also have been more likely to underreport (or at least misreport) their total pollution abatement expenditures.

There are still other reasons why the analyses here will not necessarily reveal the full effects of regulation. To the extent that heavy polluters located in attainment areas (or nonpolluting plants for that matter) undertake additional air pollution abatement voluntarily - that is, over and above what regulators might actually require of them (see Jaffe et al. 1995, Becker and Henderson 2001) - estimates of regulatory costs (based on comparisons of otherwise similar plants in attainment and non-attainment counties) may be biased downward. A further bias may be present if the establishments that choose to locate/stay in non-attainment counties are also

\footnotetext{
${ }^{23}$ In particular, in the (preferred) specification with industry effects (i.e., Tables 9-10), county TSP non-attainment status had no significant effect on either the air pollution abatement capital expenditures or operating costs of high PT emitters, nor is an effect found of $\mathrm{O}_{3}$ non-attainment on the capital investment of either high $\mathrm{VOC}$ or $\mathrm{NO}_{2}$ emitters, even though effects on their operating costs are evident.
} 
ones that are somehow inherently better able to abate pollution at less cost.

Nonetheless, despite these potential limitations, there is ample evidence here that air quality regulation led to increased air pollution abatement capital expenditures and operating costs in these manufacturing plants. Future research might look at these expenditures in more detail. For example, the establishment-level data allow one to identify capital investment devoted to the abatement of specific air pollutants, to examine the incidence of end-of-line versus change-in-production-process capital expenditures, and to relate APA capital investment with that for other pollution media (water and solid waste) as well as with investment decisions in general. Different types of APA operating expenses (labor, materials \& energy, services \& equipment leasing, and depreciation) can also be distinguished in certain years of the PACE survey. And data on tons of various air pollutants abated (collected prior to 1986) make it is possible to also consider some of the potential benefits of this air quality regulation, in addition to the costs that have been the focus of this paper. 


\section{REFERENCES}

AEI-Brookings Joint Center for Regulatory Studies, et al. AEI-Brookings Amici Curiae Brief \#00-01, July 2000.

Arora, Seema and Timothy N. Cason. "Do Community Characteristics Influence Environmental Outcomes? Evidence from the Toxic Release Inventory," Southern Economic Journal, 65(4), 691-716, April 1999.

Becker, Randy A. The Effects of Environmental Regulation on Firm Behavior. Brown University, Ph.D. dissertation, May 1998.

Becker, Randy A. and J. Vernon Henderson. "Effects of Air Quality Regulations on Polluting Industries," Journal of Political Economy, 108(2), 379-421, April 2000.

Becker, Randy A. and J. Vernon Henderson. "Costs of Air Quality Regulation," in Behavioral and Distributional Effects of Environmental Policy, Carlo Carraro and Gilbert E. Metcalf (eds.), Chicago: National Bureau of Economic Research and The University of Chicago Press, 2001.

Chay, Kenneth Y. and Michael Greenstone. "Does Air Quality Matter? Evidence from the Housing Market," University of California at Berkeley, Department of Economics, mimeograph, December 2000.

Cragg, John G. "Some Statistical Models for Limited Dependent Variables with Application to the Demand for Durable Goods," Econometrica, 39(5), 829-844, September 1971.

Dean, Thomas J., Robert L. Brown, and Victor Stango. "Environmental Regulation as a Barrier to the Formation of Small Manufacturing Establishments: A Longitudinal Examination," Journal of Environmental Economics and Management, 40(1), 56-75, July 2000.

Gray, Wayne B. "Manufacturing Plant Location: Does State Pollution Regulation Matter?" NBER Working Paper Series, 5880, January 1997.

Gray, Wayne B. and Mary E. Deily. "Compliance and Enforcement: Air Pollution Regulation in the U.S. Steel Industry," Journal of Environmental Economics and Management, 31(1), 96111, July 1996.

Gray, Wayne B. and Ronald J. Shadbegian. "Pollution Abatement Costs, Regulation, and Plantlevel Productivity,” NBER Working Paper Series, 4994, January 1995. 
Greenstone, Michael. "The Impacts of Environmental Regulations on Industrial Activity:

Evidence from the 1970 and 1977 Clean Air Act Amendments and the Census of Manufactures," NBER Working Paper Series, 8484, September 2001.

Henderson, J. Vernon. "Effects of Air Quality Regulation,” American Economic Review, 86(4), 789-813, September 1996.

Hite, Diane. "A Random Utility Model of Environmental Equity," Growth and Change, 31(1), 40-58, Winter 2000.

Jaffe, Adam B., Steven R. Peterson, Paul R. Portney, and Robert N. Stavins. "Environmental Regulation and the Competitiveness of U.S. Manufacturing: What Does the Evidence Tell Us?" Journal of Economic Literature, 33(1), 132-163, March 1995.

Kahn, Matthew E. "Particulate Pollution Trends in the United States," Regional Science and Urban Economics, 27(1), 87-107, February 1997.

Kahn, Matthew E. "The Silver Lining of Rust Belt Manufacturing Decline," Journal of Urban Economics, 46(3), 360-376, November 1999.

Kahn, Matthew E. and John G. Matsusaka. "Demand for Environmental Goods: Evidence from Voting Patterns on California Initiatives," Journal of Law and Economics, 40(1), 137-173, April 1997.

Levinson, Arik. "Environmental Regulations and Manufacturers' Location Choices: Evidence from the Census of Manufactures," Journal of Public Economics, 62(1-2), 5-29, October 1996.

Levinson, Arik. “An Industry-Adjusted Index of State Environmental Compliance Costs," in Behavioral and Distributional Effects of Environmental Policy, Carlo Carraro and Gilbert E. Metcalf (eds.), Chicago: National Bureau of Economic Research and The University of Chicago Press, 2001.

List, John A. and W. Warren McHone. "Measuring the Effects of Air Quality Regulations on "Dirty" Firm Births: Evidence from the Neo- and Mature-Regulatory Periods," Papers in Regional Science, 79(2), 177-190, April 2000.

Pashigian, B. Peter. "The Effect of Environmental Regulation on Optimal Plant Size and Factor Shares," Journal of Law and Economics, 27(1), 1-28, April 1984. 
U.S. Bureau of Economic Analysis. Survey of Current Business. Washington, DC: U.S. Government Printing Office, August 2001.

U.S. Bureau of the Census. Pollution Abatement Costs and Expenditures, 19XX. Washington, DC: U.S. Government Printing Office, various years.

U.S. Environmental Protection Agency. National Air Quality and Emission Trends Report, 1998. Research Triangle Park, NC: Office of Air Quality Planning and Standards, March 2000. 
Table 1. Distribution of sample observations, by 2-digit SIC category and by year

\begin{tabular}{|c|c|c|c|c|c|}
\hline Food and Kindred Products (SIC 20) & 14,462 & $16.09 \%$ & 1979 & 11,420 & $12.70 \%$ \\
\hline Tobacco Products (SIC 21) & 292 & $0.32 \%$ & 1980 & 10,467 & $11.64 \%$ \\
\hline Textile Mill Products (SIC 22) & 4,152 & $4.62 \%$ & 1981 & 9,188 & $10.22 \%$ \\
\hline Apparel and Other Textile Products (SIC 23) & $108^{*}$ & $0.12 \%$ & 1982 & 13,934 & $15.50 \%$ \\
\hline Lumber and Wood Products (SIC 24) & 3,324 & $3.70 \%$ & 1984 & 13,165 & $14.65 \%$ \\
\hline Furniture and Fixtures (SIC 25) & 1,684 & $1.87 \%$ & 1985 & 11,151 & $12.41 \%$ \\
\hline Paper and Allied Products (SIC 26) & 5,058 & $5.63 \%$ & 1986 & 10,337 & $11.50 \%$ \\
\hline Printing and Publishing (SIC 27) & 4,722 & $5.25 \%$ & 1988 & 10,227 & $11.38 \%$ \\
\hline Chemicals and Allied Products (SIC 28) & 8,029 & $8.93 \%$ & & & \\
\hline Petroleum and Coal Products (SIC 29) & 1,866 & $2.08 \%$ & & & \\
\hline Rubber and Miscellaneous Plastic Products (SIC 30) & 3,842 & $4.27 \%$ & & & \\
\hline Leather and Leather Products (SIC 31) & 833 & $0.93 \%$ & & & \\
\hline Stone, Clay, and Glass Products (SIC 32) & 3,121 & $3.47 \%$ & & & \\
\hline Primary Metal Industries (SIC 33) & 5,328 & $5.93 \%$ & & & \\
\hline Fabricated Metal Products (SIC 34) & 7,779 & $8.65 \%$ & & & \\
\hline Industrial Machinery and Equipment (SIC 35) & 9,529 & $10.60 \%$ & & & \\
\hline Electronic and Other Electric Equipment (SIC 36) & 7,525 & $8.37 \%$ & & & \\
\hline Transportation Equipment (SIC 37) & 4,200 & $4.67 \%$ & & & \\
\hline Instruments and Related Products (SIC 38) & 2,429 & $2.70 \%$ & & & \\
\hline Miscellaneous Manufacturing Industries（SIC 39） & 1,606 & $1.79 \%$ & & & \\
\hline
\end{tabular}


Table 2. Summary of capital expenditures and operating costs (in 1988 dollars)

\section{Capital Expenditures}

Number of establishment

Total outlays

Air pollution abatement outlays

(percent of total outlays)

Average air pollution abatement outlays per plant

Number (and percent) of establishments with positive air pollution abatement outlays

Average air pollution abatement outlays per plant given positive outlays
89,889

$\$ 403.2$ billion

$\$ 13.3$ billion

$(3.3 \%)$

$\$ 148,198$

20,620

(22.9\%)

$\$ 646,041$ $\underline{\underline{\text { Operating Costs }}}$

89,889

$\$ 7,785.0$ billion

$\$ 28.5$ billion

$(0.4 \%)$

$\$ 316,885$

41,772

$(46.5 \%)$

$\$ 681,903$

Table 3. "High emitters" of criteria air pollutants

\section{Number (and percent) of establishments}

Volatile Organic Compounds (VOC)

Nitrogen Dioxide $\left(\mathrm{NO}_{2}\right)$

Particulates (PT)

Carbon Monoxide (CO)

Sulfur Dioxide $\left(\mathrm{SO}_{2}\right)$

Lead (Pb)
43,686

$(48.5 \%)$

38,904

$(43.3 \%)$

39,660

(44.1\%)

17,342

$(19.3 \%)$

37,291

$(41.5 \%)$

4,584

$(5.1 \%)$
Number (and percent) of industries

135

(30\%)

116 $(26 \%)$

135 (30\%)

$(11 \%)$

118 (26\%)

15 (3\%) 
Table 4. Description of county characteristics

\begin{tabular}{|c|c|c|}
\hline & $\begin{array}{c}\text { Mean } \\
\text { (Std. Dev.) } \\
\end{array}$ & Description \\
\hline Population density & $\begin{array}{c}1,611 \\
(5,446)\end{array}$ & Persons per square mile. \\
\hline Homeownership & $\begin{array}{c}65.8 \\
(10.7)\end{array}$ & $\begin{array}{l}\text { Percent of occupied housing units that are } \\
\text { owner-occupied. }\end{array}$ \\
\hline Unemployment & $\begin{array}{l}6.66 \\
(2.39)\end{array}$ & $\begin{array}{l}\text { Percent of civilian labor force (16 years and older) } \\
\text { that is unemployed. }\end{array}$ \\
\hline Manufacturing & $\begin{array}{l}26.2 \\
(9.3)\end{array}$ & $\begin{array}{l}\text { Percent of employed civilian labor force (16 years } \\
\text { and older) employed in manufacturing. }\end{array}$ \\
\hline Income & $\begin{array}{c}7,271 \\
(1,301)\end{array}$ & Per capita money income (in dollars). \\
\hline Sensitive population & $\begin{array}{l}18.4 \\
(2.6)\end{array}$ & $\begin{array}{l}\text { Percent of population under } 5 \text { years of age or } 65 \\
\text { years and over. }\end{array}$ \\
\hline Doctors & $\begin{array}{c}195 \\
(139)\end{array}$ & $\begin{array}{l}\text { Active, non-federal physicians per } 100,000 \\
\text { population (1985). }\end{array}$ \\
\hline Education & $\begin{array}{l}15.6 \\
(6.0)\end{array}$ & $\begin{array}{l}\text { Percent of population ( } 25 \text { years and older) with } \\
\text { at least a bachelor's degree. }\end{array}$ \\
\hline Democrats & $\begin{array}{c}40.5 \\
(10.2)\end{array}$ & $\begin{array}{l}\text { Percent of (major party) votes cast for Democratic } \\
\text { presidential candidate (1984). }\end{array}$ \\
\hline Nonwhite & $\begin{array}{c}15.8 \\
(13.5)\end{array}$ & Percent of population that is nonwhite. \\
\hline Foreign-born & $\begin{array}{c}5.3 \\
(5.8)\end{array}$ & Percent of population that is foreign-born. \\
\hline Polluters & $\begin{array}{c}93 \\
(38)\end{array}$ & $\begin{array}{l}\text { "Polluting" manufacturing establishments per } \\
\text { 100,000 population (1982). }\end{array}$ \\
\hline
\end{tabular}

\footnotetext{
${ }^{a}$ These data were compiled by the American Medical Association from its Physician Masterfile and were extracted from the Census Bureau's County and City Data Book 1988.

${ }^{\mathrm{b}}$ The underlying election data were compiled by the Elections Research Center.

${ }^{c}$ This variable was constructed using 1982 Census of Manufactures microdata and the definition of high air pollution emitting industries from above.
} 
Table 5. Establishments subject to greater local regulation, by pollutant

\author{
Number \\ (and percent) \\ of establishments
}

High VOC emitter in $\mathrm{O}_{3}$ non-attainment county

27,269

$(30.3 \%)$

High $\mathrm{NO}_{2}$ emitter in $\mathrm{O}_{3}$ non-attainment county

22,712

$(25.3 \%)$

High PT emitter in TSP non-attainment county

18,933

$(21.1 \%)$

High CO emitter in $\mathrm{CO}$ non-attainment county

5,135

$(5.7 \%)$

High $\mathrm{SO}_{2}$ emitter in $\mathrm{SO}_{2}$ non-attainment county

3,641

$(4.1 \%)$

At least one of the above five situations

39,766

(44.2\%) 
Table 6. Regression results on air pollution abatement capital expenditures (1st of 3 pages)

\section{Observations}

Pseudo R-squared

Predicted Probability | Observed Probability

\section{General Control Variables}

Constant

Year effects (1979-82, 1984-86, 1988)

State effects (49 contiguous)

\section{Establishment Characteristics}

Employment

Employment squared

Employment cubed

Belongs to a multi-unit firm

1 "generation" old

2 "generations" old

3 "generations" old

4+ "generations" old
Probit

Capital Exp $>0$

Change in probability

(at variable means)

\author{
89,889 \\ 0.1530 \\ 19.55\% | 22.94\%
}

Tobit

Capital Expenditure

in $\$ 1000$

(1988 dollars)

$\mathbf{8 9 , 8 8 9}$

0.0303

yes

yes

yes

$$
\begin{aligned}
& +\mathbf{0 . 0 1 4 0} \\
& (0.0004)
\end{aligned}
$$

$-1.25 \mathrm{E}-06 * *$

(9.17E-08)

$+3.01 \mathrm{E}-11 * *$

(3.76E-12)

$+10.69 * *$

(0.39)

$+2.41 * *$

(1.19)

$+4.56 * *$

(1.19)

$+5.34 * *$

(1.20)

$+\mathbf{8 . 0 8} * *$

(0.89)
$+1.33 * *$

(0.03)

$-9.91 \mathrm{E}-05 * *$

(3.87E-06)

+2.07E-09**

(1.09E-10)

$+1,289.9 * *$

(70.8)

$+244.9 *$

(136.8)

+479.7**

(131.0)

$+542.2 * *$

(130.5)

$+\mathbf{8 9 8 . 0}$ **

(121.3)

\section{County Characteristics}

Population density

Population density squared

Homeownership

Homeownership squared

Income

Income squared

Income cubed

$$
\text { -9.03E-05 }
$$

(1.64E-04)

-8.49E-09**

(2.52E-09)

$-\mathbf{0 . 3 7 5 *}$

(0.201)

+2.99E-03*

(1.55E-03)

$+\mathbf{0 . 0 2 8 8}^{* *}$

(0.0058)

$-3.55 \mathrm{E}-06 * *$

(7.85E-07)

$\mathbf{- 0 . 0 3 4 5 *}$

(0.0198)

$-8.43 \mathrm{E}-07 * *$

(3.38E-07)

$-62.7 * *$

(23.7)

$+\mathbf{0 . 5 2 2} * *$

(0.182)

$+\mathbf{2 . 7 9} * *$

(0.74)

-3.36E-04**

(9.96E-05)

$+1.34 \mathrm{E}-08 * *$

(3.45E-11) 
Table 6. Regression results on air pollution abatement capital expenditures (continued, 2 of 3)

\section{County Characteristics (continued)}

Probit

\section{Capital Exp > 0}

Change in probability

(at variable means)
Tobit

Capital Expenditure

in $\$ 1000$

(1988 dollars)
Unemployment

Unemployment squared

Manufacturing

Manufacturing squared

Sensitive population

Sensitive population squared

Doctors

Doctors squared

Doctors cubed

Education

Education squared

Democrats

Democrats squared

Nonwhite

Nonwhite squared

Foreign-born

Foreign-born squared

Polluters

Polluters squared

Polluters cubed

$$
\mathbf{- 0 . 0 4 5 6}
$$

(0.3453)

-7.77E-03

(0.0184)

$+\mathbf{0 . 6 2 9} * *$

(0.092)

$\mathbf{- 0 . 0 1 0 2 * *}$

(0.0015)

$-1.65 * *$

(0.58)

+0.0318 **

(0.0140)

$+\mathbf{0 . 0 1 0 5}$

(0.0065)

-1.31E-05

(1.17E-05)

+4.95E-11

(5.00E-11)

$\mathbf{- 0 . 1 0 1}$

(0.190)

-2.71E-03

(4.66E-03)

$+0.241 * *$

(0.118)

-2.35E-03

(1.43E-03)

$\mathbf{- 0 . 0 1 2 4}$

(0.0515)

-1.15E-04

(9.51E-04)

$-0.330 * *$

(0.152)

$+3.53 \mathrm{E}-03$

(4.70E-03)

$-\mathbf{0 . 1 0 6} * *$

(0.037)

$+5.55 \mathrm{E}-04 * *$

(2.69E-04)

-1.04E-06*

(5.43E-07)
$+32.6$

(41.1)

-3.12

(2.18)

$+63.0 * *$

(10.7)

-1.05 **

(0.18)

$\mathbf{- 5 5 . 2}$

(69.7)

$+\mathbf{0 . 6 1 0}$

(1.694)

$+\mathbf{0 . 8 5 4}$

(0.764)

-2.05E-03

(1.37E-03)

+9.18E-07

(5.86E-07)

$-28.3$

(22.4)

$+\mathbf{0 . 2 0 5}$

(0.549)

$\mathbf{- 5 . 4 3}$

(14.03)

$+\mathbf{0 . 2 3 4}$

(0.169)

$+\mathbf{8 . 8 8}$

(6.19)

$-0.190 *$

(0.114)

$-23.1$

(18.4)

$+\mathbf{+ 0 . 1 7 5}$

(0.583)

-16.8 **

(3.2)

$+0.0912 * *$

(0.0209)

-1.58E-04**

(3.84E-05) 
Table 6. Regression results on air pollution abatement capital expenditures (continued, 3 of 3)

Emission Characteristics (of 4-digit SIC)

Probit

\section{Capital Exp > 0}

Change in probability

(at variable means)
Tobit

Capital Expenditure

in $\$ 1000$

(1988 dollars)
High VOC emitter

High nitrogen dioxide $\left[\mathrm{NO}_{2}\right]$ emitter

High particulate $[\mathrm{PT}]$ emitter

High carbon monoxide [CO] emitter

High sulfur dioxide $\left[\mathrm{SO}_{2}\right]$ emitter

$$
+4.16 * *
$$$$
(0.52)
$$$$
+0.37
$$$$
\text { (0.65) }
$$

$+7.89 * *$

$(0.51)$

$+12.69 * *$

(0.56)

$+3.96 * *$

$(0.48)$
$+343.5 * *$

(63.2)

$-51.0$

(77.2)

$+802.5^{* *}$

(60.9)

$+1,379.7 * *$

$+465.2 * *$

(56.0)

\section{County NAAQS Attainment Statuses (at t-1)}

Ozone [ $\left.\mathrm{O}_{3}\right]$ non-attainment

$+1.43 * *$

$+\mathbf{1 1 9 . 3}$

(0.63)

(76.9)

Particulate [TSP] non-attainment

$+0.81$

$+\mathbf{5 1 . 0}$

$(0.53)$

(65.3)

Carbon monoxide $[\mathrm{CO}]$ non-attainment

$-1.15 * *$

$-199.0 * *$

$(0.54)$

(65.8)

Sulfur dioxide [ $\left.\mathrm{SO}_{2}\right]$ non-attainment

$-1.74 * *$

$-161.0 *$

$(0.73)$

(91.4)

\section{Establishment Subject to Local Regulation}

High VOC emitter $* \mathrm{O}_{3}$ non-attainment

$-1.77 * *$

$-53.1$

$(0.62)$

(77.1)

High $\mathrm{NO}_{2}$ emitter $* \mathrm{O}_{3}$ non-attainment

$+0.56$

$+8.8$

(0.66)

(80.1)

High PT emitter * TSP non-attainment

$+2.41 * *$

$+170.9 * *$

(0.63)

(72.6)

High $\mathrm{CO}$ emitter $* \mathrm{CO}$ non-attainment

$+0.49$

$+285.0 * *$

(0.75)

(83.1)

High $\mathrm{SO}_{2}$ emitter $* \mathrm{SO}_{2}$ non-attainment

$+2.25 * *$

$+432.6 * *$

(1.00) 
Table 7. Regression results on air pollution abatement operating costs (1st of 3 pages)

Probit

Operating Costs $>0$

Change in probability

(at variable means)

\section{Observations}

Pseudo R-squared

Predicted Probability | Observed Probability

Constant

Year effects (1979-82, 1984-86, 1988)

State effects (49 contiguous)

\section{Establishment Characteristics}

Employment

Employment squared

Employment cubed

Belongs to a multi-unit firm

1 "generation" old

2 "generations" old

3 "generations" old

4+ "generations" old

89,889

0.1809

\begin{tabular}{l|l}
$47.23 \%$ & $\mathbf{4 6 . 4 7 \%}$
\end{tabular}

yes

yes

yes

\section{General Control Variables}

$$
\begin{gathered}
+\mathbf{0 . 0 3 1 2} * * \\
(0.0008) \\
\mathbf{- 4 . 2 9 E - 0 6 * *} \\
(2.75 \mathrm{E}-07) \\
+\mathbf{1 . 6 8 E}-10 * * \\
(1.91 \mathrm{E}-11) \\
+\mathbf{1 9 . 7 4} * * \\
(0.57) \\
+\mathbf{5 . 7 2} * * \\
(1.33) \\
+\mathbf{8 . 4 6} * * \\
(1.27) \\
+\mathbf{7 . 7 8}^{* *} \\
(1.27) \\
+\mathbf{1 4 . 5 6}^{* *} \\
(1.13)
\end{gathered}
$$

Tobit

\section{Operating Costs}

in $\$ 1000$

(1988 dollars)

89,889

0.0213

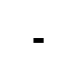

yes
yes
yes

$$
+1.41 * *
$$

(0.03)

$-1.03 E-04 * *$

(3.89E-06)

$+2.09 \mathrm{E}-09 * *$

(1.12E-10)

$+1,379.5 * *$

(56.9)

$+392.1 * *$

(113.6)

$+\mathbf{5 4 6 . 0} * *$

(109.2)

$+\mathbf{5 4 4 . 1} * *$

(108.9)

$+1,032.3^{* *}$

(100.5)

\section{County Characteristics}

Population density

Population density squared

Homeownership

Homeownership squared

Income

$\begin{array}{lc}\mathbf{- 1 . 4 2 E - 0 3 * *} & \mathbf{- 0 . 0 4 4 6 * *} \\ (2.10 \mathrm{E}-04) & (0.0171) \\ \mathbf{+ 1 . 0 8 E - 0 8 * *} & \mathbf{+ 2 . 5 1 E - 0 7} \\ (2.80 \mathrm{E}-09) & (2.30 \mathrm{E}-07) \\ \mathbf{- 0 . 9 1 3} * * & \mathbf{- 1 5 . 7} \\ (0.261) & (21.3) \\ \mathbf{+ 7 . 2 9 E - 0 3 * *} & \mathbf{+ 0 . 1 8 8} \\ (2.01 \mathrm{E}-03) & (0.163) \\ \mathbf{+ 0 . 0 3 6 1 * *} & \mathbf{+ 1 . 6 5 * *} \\ (0.0076) & (0.64) \\ \mathbf{- 4 . 0 4 E - 0 6 * *} & \mathbf{- 1 . 6 3 E - 0 4 *} \\ (1.03 \mathrm{E}-06) & (8.69 \mathrm{E}-05) \\ \mathbf{+ 1 . 4 2 E - 1 0 * *} & \mathbf{+ 5 . 4 1 E - 0 9} \\ (4.53 \mathrm{E}-11) & (3.84 \mathrm{E}-09)\end{array}$

Income squared

Income cubed 
Table 7. Regression results on air pollution abatement operating costs (continued, 2 of 3)

\section{County Characteristics (continued)}

Probit

Operating Costs $>0$

Change in probability

(at variable means)
Tobit

Operating Costs

in $\$ 1000$

(1988 dollars)
Unemployment

Unemployment squared

Manufacturing

Manufacturing squared

Sensitive population

Sensitive population squared

Doctors

Doctors squared

Doctors cubed

Education

Education squared

Democrats

Democrats squared

Nonwhite

Nonwhite squared

Foreign-born

Foreign-born squared

Polluters

Polluters squared

Polluters cubed

$\mathbf{- 0 . 5 3 8}$
$(0.488)$
$\mathbf{- 0 . 0 2 5}$
$(0.027)$
$+\mathbf{0 . 8 2 6} * *$
$(0.119)$
$\mathbf{- 0 . 0 1 3 0}^{* *}$
$(0.0020)$

$-2.41 * *$

(0.74)

$+\mathbf{0 . 0 4 7 2}$ **

(0.0178)

$+\mathbf{0 . 0 1 4 7 *}$

(0.0086)

-3.17E-05**

(1.53E-05)

$+1.49 \mathrm{E}-08 * *$

(6.56E-09)

-0.491*

(0.252)

+1.72E-03

(6.09E-03)

-0.260 *

(0.155)

+4.88E-03**

(1.87E-03)

$\mathbf{+ 0 . 0 3 2 3}$

(0.0682)

-8.86E-04

(1.24E-03)

$+0.343 *$

(0.199)

$\mathbf{- 0 . 0 1 3 9 * *}$

(0.0061)

$\mathbf{- 0 . 0 7 9 * *}$

(0.030)

+1.75E-04

(1.72E-04)

-4.38E-08

(2.58E-07) $\mathbf{+ 4 8 . 0}$

(36.2)

-3.58*

(1.91)

$+56.3 * *$

(9.5)

$-0.900 * *$

(0.157)

$\mathbf{- 9 2 . 2}$

(61.1)

$+1.13$

(1.47)

$\mathbf{- 0 . 0 5 3}$

(0.681)

-7.33E-04

(1.22E-03)

+5.09E-07

(5.21E-07)

$-66.7 * *$

(20.1)

$+\mathbf{0 . 5 5 4}$

(0.491)

-1.14

(12.51)

$+0.197$

(0.151)

$+6.17$

(5.49)

$\mathbf{- 0 . 0 4 6}$

(0.101)

$+81.3 * *$

(16.3)

$-2.59 * *$

(0.51)

$-17.7 * *$

$+0.0713 * *$

(0.0143)

-8.24E-05**

(2.20E-05) 
Table 7. Regression results on air pollution abatement operating costs (continued, 3 of 3)

\section{Emission Characteristics (of 4-digit SIC)}

Probit

Operating Costs $>0$

Change in probability

(at variable means)
Tobit

Operating Costs

in $\$ 1000$

(1988 dollars)
High VOC emitter

High nitrogen dioxide $\left[\mathrm{NO}_{2}\right]$ emitter

High particulate $[\mathrm{PT}]$ emitter

High carbon monoxide [CO] emitter

High sulfur dioxide $\left[\mathrm{SO}_{2}\right]$ emitter $+\mathbf{8 . 3 7 * *}$

(0.65)

$+4.09 * *$

$(0.82)$

$+13.87 * *$

$(0.63)$

$+17.63^{* *}$

$(0.67)$

$+7.78 * *$

$(0.62)$
$+205.7 * *$

(54.4)

$-153.5 * *$

(67.2)

$+847.8 * *$

$(53.2)$

$+1,586.0 * *$

$(50.2)$

$+637.3^{* *}$

(49.4)

\section{County NAAQS Attainment Statuses (at t-1)}

Ozone [ $\left.\mathrm{O}_{3}\right]$ non-attainment

$+1.72 * *$

$-74.1$

(0.79)

(66.8)

Particulate [TSP] non-attainment

$+\mathbf{0 . 5 8}$

$-66.2$

$(0.66)$

(56.5)

Carbon monoxide $[\mathrm{CO}]$ non-attainment

$-1.25 *$

$-340.1 * *$

$(0.71)$

(58.5)

$-1.58 *$

$+66.2$

$(0.95)$

(80.3)

\section{Establishment Subject to Local Regulation}

High VOC emitter * $\mathrm{O}_{3}$ non-attainment

$-3.17 * *$

$(0.81)$

$+179.1 * *$

$-1.23$

(67.0)

High $\mathrm{NO}_{2}$ emitter $* \mathrm{O}_{3}$ non-attainment

$+80.5$

(69.9)

High PT emitter * TSP non-attainment

$+4.99 * *$

(0.80)

$+260.3 * *$

(64.4)

High $\mathrm{CO}$ emitter $* \mathrm{CO}$ non-attainment

$-2.29 * *$

$+241.4 * *$

(78.6)

High $\mathrm{SO}_{2}$ emitter $* \mathrm{SO}_{2}$ non-attainment 
Table 8. Effects of air quality regulation

\begin{tabular}{|c|c|c|c|c|}
\hline & \multicolumn{2}{|c|}{ APA Capital Expenditures } & \multicolumn{2}{|c|}{ APA Operating Costs } \\
\hline & $\begin{array}{r}\text { County } \mathrm{O}_{3} \\
\text { Attainment } \\
\end{array}$ & $\begin{array}{c}\text { County } \mathrm{O}_{3} \\
\text { Non-attainment } \\
\end{array}$ & $\begin{array}{r}\text { County } \mathrm{O}_{3} \\
\text { Attainment } \\
\end{array}$ & $\begin{array}{c}\text { County } \mathrm{O}_{3} \\
\text { Non-attainment } \\
\end{array}$ \\
\hline $\begin{array}{l}\text { Low VOC emitter } \\
\text { High VOC emitter }\end{array}$ & $+\$ 343,500$ & $\begin{array}{c}+0 \\
+\$ 343,500\end{array}$ & $+\$ 205,700$ & $\begin{array}{c}+0 \\
+\$ 384,800\end{array}$ \\
\hline $\begin{array}{l}\text { \% state and federal } \\
\% \text { of total outlays }\end{array}$ & \multicolumn{2}{|c|}{$100 \%$} & \multicolumn{2}{|c|}{$53 \%$} \\
\hline & $\begin{array}{l}\text { County TSP } \\
\text { Attainment } \\
\end{array}$ & $\begin{array}{c}\text { County TSP } \\
\text { Non-attainment } \\
\end{array}$ & $\begin{array}{l}\text { County TSP } \\
\text { Attainment }\end{array}$ & $\begin{array}{c}\text { County TSP } \\
\text { Non-attainment } \\
\end{array}$ \\
\hline $\begin{array}{l}\text { Low PT emitter } \\
\text { High PT emitter }\end{array}$ & $+\$ \overline{802,500}$ & $\begin{array}{c}+0 \\
+\$ 973,400\end{array}$ & $+\overline{\$ 847,800}$ & $\begin{array}{c}+0 \\
+\$ 1,108,100\end{array}$ \\
\hline \multirow[t]{2}{*}{$\begin{array}{l}\text { \% state and federal } \\
\% \text { of total outlays }\end{array}$} & \multicolumn{2}{|r|}{$82 \%$} & \multicolumn{2}{|r|}{$0.77 \%$} \\
\hline & $\begin{array}{l}\text { County CO } \\
\text { Attainment }\end{array}$ & $\begin{array}{c}\text { County CO } \\
\text { Non-attainment } \\
\end{array}$ & $\begin{array}{l}\text { County CO } \\
\text { Attainment } \\
\end{array}$ & $\begin{array}{c}\text { County CO } \\
\text { Non-attainment } \\
\end{array}$ \\
\hline $\begin{array}{l}\text { Low CO emitter } \\
\text { High CO emitter }\end{array}$ & $+\$ 1,379,700$ & $\begin{array}{c}-\$ 199,000 \\
+\$ 1,465,700\end{array}$ & $+\$ 1,586,000$ & $\begin{array}{c}-\$ 340,100 \\
+\$ 1,487,300\end{array}$ \\
\hline \multirow[t]{2}{*}{$\begin{array}{l}\% \text { state and federal } \\
\% \text { of total outlays }\end{array}$} & \multicolumn{2}{|c|}{$94 \%$} & \multicolumn{2}{|c|}{$107 \%$} \\
\hline & $\begin{array}{l}\text { County } \mathrm{SO}_{2} \\
\text { Attainment }\end{array}$ & $\begin{array}{c}\text { County } \mathrm{SO}_{2} \\
\text { Non-attainment } \\
\end{array}$ & $\begin{array}{l}\text { County } \mathrm{SO}_{2} \\
\text { Attainment } \\
\end{array}$ & $\begin{array}{c}\text { County } \mathrm{SO}_{2} \\
\text { Non-attainment } \\
\end{array}$ \\
\hline $\begin{array}{l}\text { Low } \mathrm{SO}_{2} \text { emitter } \\
\text { High } \mathrm{SO}_{2} \text { emitter }\end{array}$ & $+\$ 465,200$ & $\begin{array}{l}-\$ 161,000 \\
+\$ 736,800\end{array}$ & $+\$ \overline{637}, 300$ & $\begin{array}{c}+0 \\
+\$ 1,155,200\end{array}$ \\
\hline $\begin{array}{l}\text { \% state and federal } \\
\% \text { of total outlays }\end{array}$ & \multicolumn{2}{|r|}{$63 \%$} & \multicolumn{2}{|c|}{$55 \%$} \\
\hline
\end{tabular}


Table 9. Partial regression results on APA capital expenditures, with industry effects Probit

Tobit

\section{Capital Exp $>0$}

Change in probability
Capital Expenditure

in $\$ 1000$

Observations

$\mathbf{8 8 , 8 6 1}$

89,889

Pseudo R-squared

0.2465

0.0452

Establishment Subject to Local Regulation

High VOC emitter $* \mathrm{O}_{3}$ non-attainment

$+0.22$

$+\mathbf{1 0 6 . 3}$

(0.65)

High $\mathrm{NO}_{2}$ emitter $* \mathrm{O}_{3}$ non-attainment

$\mathbf{- 0 . 8 8}$

$-104.7$

(0.66)

High PT emitter * TSP non-attainment

$+1.21 *$

$+53.4$

$(0.63)$

(75.7)

High $\mathrm{CO}$ emitter $* \mathrm{CO}$ non-attainment

$+1.58 * *$

$+323.8 * *$

$(0.79)$

High $\mathrm{SO}_{2}$ emitter $* \mathrm{SO}_{2}$ non-attainment

$+1.73 *$

+315.8 **

$(0.98)$

Table 10. Partial regression results on APA operating costs, with industry effects

Probit

Operating Costs $>0$

Change in probability

Observations

Pseudo R-squared

Establishment Subject to Local Regulation

High VOC emitter * $\mathrm{O}_{3}$ non-attainment

High $\mathrm{NO}_{2}$ emitter $* \mathrm{O}_{3}$ non-attainment

High PT emitter * TSP non-attainment

High $\mathrm{CO}$ emitter $* \mathrm{CO}$ non-attainment

High $\mathrm{SO}_{2}$ emitter $* \mathrm{SO}_{2}$ non-attainment
89,603

0.3238

$+\mathbf{1 . 0 1}$

(0.92)

$-\mathbf{0 . 3 9}$

(0.95)

$-0.27$

(0.89)

$-1.53$

(1.27)

$+\mathbf{0 . 3 3}$

(1.44)
Tobit Operating Costs in $\$ 1000$

89,889

0.0377

$+288.0 * *$

(66.3)

$+123.7 *$

(68.2)

$+39.9$

(63.1)

$+287.3^{* *}$

(76.2)

$+187.9 * *$

(95.6) 
Table 11. Industries with the highest (conditional) plant-level air pollution abatement capital expenditures and operating costs

\section{Capital Expenditures}

1. Primary copper (SIC 3331)

2. Petroleum refining (SIC 2911)

3. Primary lead (SIC 3332)

4. Primary aluminum (SIC 3334)

5. Minerals, ground or treated (SIC 3295)

6. Alkalies and chlorine (SIC 2812)

7. Wet corn milling (SIC 2046)

8. Pulp mills (SIC 2611)

9. Petroleum and coal products, n.e.c. (SIC 2999)

10. Primary nonferrous metals, n.e.c. (SIC 3339)

11. Primary zinc (SIC 3333)

12. Hydraulic cement (SIC 3241)

13. Phosphatic fertilizers (SIC 2874)

14. Cyclic crudes and intermediates (SIC 2865)

15. Industrial organic chemicals, n.e.c. (SIC 2869)

16. Storage batteries (SIC 3691)

17. Industrial inorganic chemicals, n.e.c. (SIC 2819)

18. Soybean oil mills (SIC 2075)

19. Secondary nonferrous metals (SIC 3341)

20. Agricultural chemicals, n.e.c. (SIC 2879)

\section{Operating Costs}

1. Primary copper (SIC 3331)

2. Petroleum refining (SIC 2911)

3. Primary lead (SIC 3332)

4. Primary aluminum (SIC 3334)

5. Primary zinc (SIC 3333)

6. Blast furnaces and steel mills (SIC 3312)

7. Electrometallurgical products (SIC 3313)

8. Phosphatic fertilizers (SIC 2874)

9. Hydraulic cement (SIC 3241)

10. Primary nonferrous metals, n.e.c. (SIC 3339)

11. Petroleum and coal products, n.e.c. (SIC 2999)

12. Pulp mills (SIC 2611)

13. Alkalies and chlorine (SIC 2812)

14. Lime (SIC 3274)

15. Nitrogenous fertilizers (SIC 2873)

16. Particleboard (SIC 2492)

17. Die-cut paper and board (SIC 2645)

18. Industrial organic chemicals, n.e.c. (SIC 2869)

19. Inorganic pigments (SIC 2816)

20. Mineral wool (SIC 3296) 
Table 12. Partial Tobit regression results: The impact of establishment characteristics

Capital Expenditure Operating Costs

\section{Observations}

Pseudo R-squared

Industry effects

Establishment Characteristics

Employment

Employment squared

Employment cubed

Belongs to a multi-unit firm

1 "generation" old

2 "generations" old

3 "generations" old

4+ "generations" old

\section{Establishment Subject to Local Regulation}

* Employment

* Employment squared

* Employment cubed

* Belongs to a multi-unit firm

* 1 "generation" old

* 2 "generations" old

* 3 "generations" old

* 4+ "generations" old $\mathbf{8 9 , 8 8 9}$

$\mathbf{8 9 , 8 8 9}$

0.0456

yes

$+1.565 * *$

(0.039)

$-1.28 \mathrm{E}-04 * *$

(4.82E-06)

$+2.77 \mathrm{E}-09 * *$

(1.32E-10)

$+951.6 * *$

(82.5)

$+97.2$

(150.9)

$+325.1 * *$

(144.5)

$+350.7 * *$

(144.0)

$+\mathbf{5 4 5 . 9} * *$

(134.5)

$-151.1$

(355.1)

$\mathbf{+ 0 . 1 0 5}$

(0.067)

$+2.83 \mathrm{E}-05^{* * *}$

(8.59E-06)

$-7.54 \mathrm{E}-10 * *$

(2.44E-10)

$-146.5$

(174.2)

$+\mathbf{1 9 2 . 7}$

(360.9)

$+275.6$

(345.5)

$+321.5$

(343.5)

$+326.3$

(316.1)
0.0387

yes

$$
+1.556 \text { ** }
$$

(0.034)

\section{$-1.35 \mathrm{E}-04 * *$}

(4.43E-06)

+2.98E-09**

(1.24E-10)

$+955.8 * *$

(61.0)

$+314.6^{* *}$

(116.8)

$+450.2 * *$

(112.4)

$+392.4 * *$

(112.2)

$+637.1 * *$

(104.3)

$-223.8$

(281.9)

$+0.597 * *$

(0.063)

+2.34E-05**

(8.28E-06)

-1.11E-09**

(2.39E-10)

$+35.1$

(140.2)

$-215.2$

(290.0)

$-60.2$

(277.3)

$+44.2$

(276.8)

$+39.5$

(250.8) 
Figure 1. Predicted air pollution abatement expenditures: Industrial organic chemicals industry

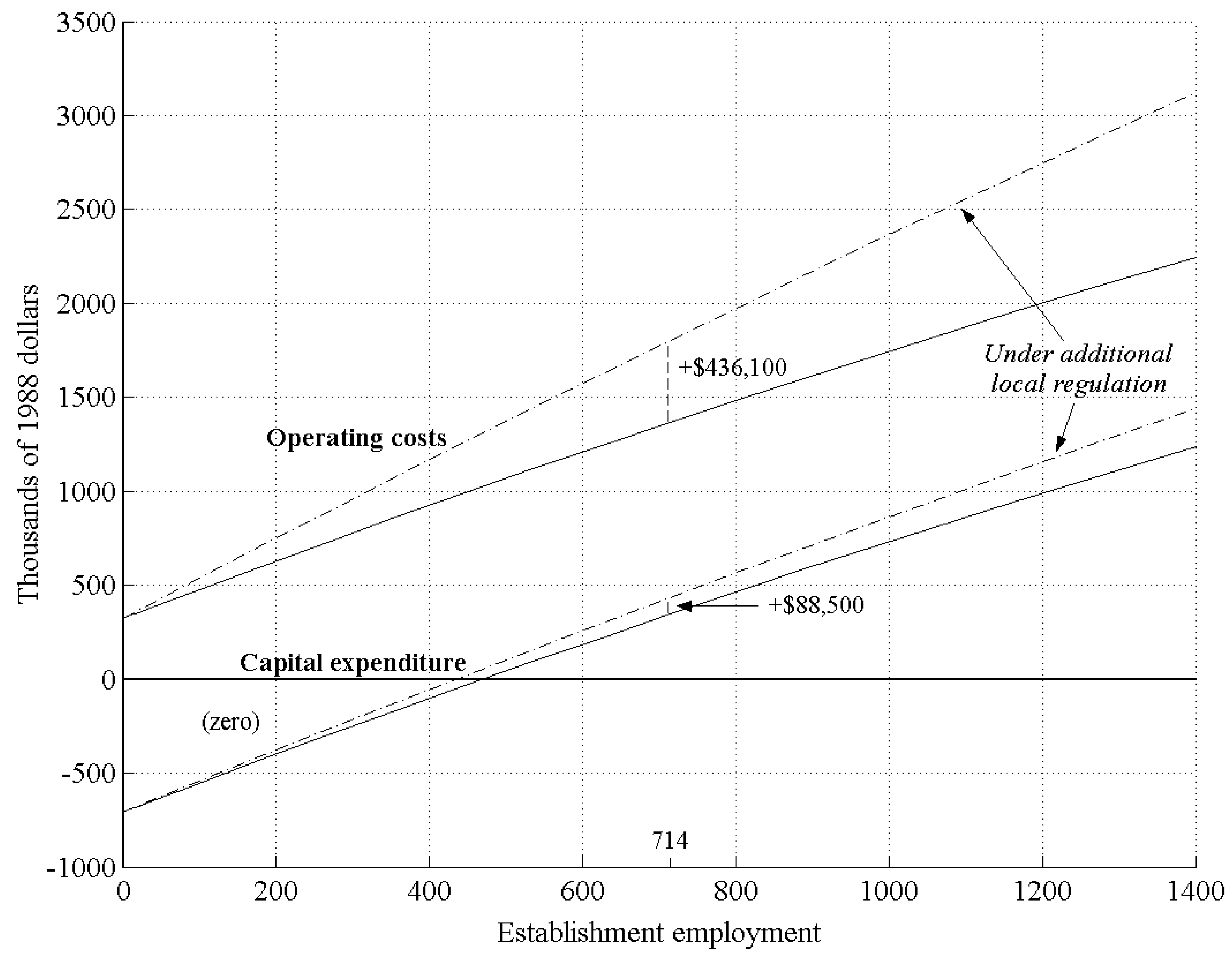




\section{APPENDIX}

\section{Sample selection criteria}

Table A-1 shows the number of establishments, by year, as we move from the original data files to the sample actually used in my empirical investigation. I will now offer a brief description of the criteria used to arrive at this final sample.

156,417 manufacturing establishments were selected by the Census Bureau to receive the PACE survey over the 8 years under study here. My first restriction is that these establishments also be in the contemporaneous Annual Survey of Manufactures (ASM) and that the data in the two files can be readily linked. This eliminates nearly $22.7 \%$ of cases, resulting in 120,969 remaining cases.

I then drop cases that I deem to be PACE survey non-response cases. Since there is no single variable in the PACE data files to indicate survey response, I need to construct such an indicator. In the 1979-1982 files, I assume survey response is indicated by a non-missing nonzero response to any of the expenditure items [RAIREOL, RAIRCPP, RAIRCAP, RWATEOL, RWATCPP, RWATCAP, RSWCAP, RAOC, RSEWER, RMWCOLL] or the establishment reported a validreason for not having positive expenditures for any of these items

$[\mathrm{NP}=(1,2,3,4)]$. In the 1984-1988 files, the identification of survey response cases is conceptually similar, though the variables differ. For these years, I assume survey response is indicated by a non-missing non-zero value for any of the expenditure items [AIREOL, AIRCPP, AIRCAP, WATEOL, WATCPP, WATCAP, SWCAP, ATOT, WTOT, HTOT, NHTOT, SEWER, MWCOLL] or the establishment reported a valid reason for not having positive expenditures for any of these items [one non-missing value among the flags NP, CI, L5, and OT]. A non-zero non-missing value to an expenditure item is not snfficient if its respective data flag indicates that the value was imputed [a flag of "IM" or "M"]. In 1988, the "excese" variables [NP, CI, L5, OT] do not exist. In this year, I use the operational status variable instead [ROPER=1]. All told, some 14,878 establishments (of the 120,969) are dropped for what I deem to be PACE survey non-response, leaving 106,091 establishments.

Next, I drop some cases with PACE data that are either insufficient, unreasonable, or reasonably suspicious, and directly affect the construction of my variables of interest. In the 1979-1982 files, this involves the three variables describing the proportion of operating costs attributable to air, water, and solid waste pollution abatement [RAVC, RWVC, and RSWVC, respectively]. I drop cases where operating costs [AOC] are positive and the shares either sum to zero or something less than 90 or greater than 110 (assuming missing values equal zero). (See below for further details on actual data construction and assumptions made about missing values, item non-response, and so forth.) In the 1984-1988 files, I drop cases with positive air pollution abatement operating costs [ATOT] that have a data flag [ATOTF] that indicates that the value was imputed ["IM" or "M"]. In addition, I drop cases with zero (or missing) ATOT if and only if none of the other operating costs [WTOT, HTOT, NHTOT] take on a positive value that wasn't imputed and at least one of the other operating costs actually takes on a positive value

\footnotetext{
${ }^{\dagger}$ An exception to this last clause, affecting only 1980 and 1981 cases, is if the establishment actually had nonmissing non-zero values for the variables that the Census Bureau actually tabulated on [AIRCAP, WATCAP, SWCAP, AOC, SEWER, MWCOLL]. It is not clear why these cases exist. These may be imputed cases or late filings. In the absence of a clear understanding of these cases, it was decided to assume that they were not response cases.

t† The data flags on the capital variables are ignored, regardless of their actual value, since these items are not imputed by the Census Bureau.
} 
Table A-1. Sample size and sample selection criteria

\begin{tabular}{|c|c|c|c|c|c|c|c|}
\hline & $\begin{array}{c}\text { Original } \\
\text { PACE } \\
\text { Samples } \\
\end{array}$ & $\begin{array}{c}\text { Matched } \\
\text { PACE-ASM } \\
\text { Samples } \\
\end{array}$ & $\begin{array}{c}\text { PACE Survey } \\
\text { Non-response } \\
\text { Cases } \\
\end{array}$ & $\begin{array}{l}\text { Additional } \\
\text { PACE } \\
\text { Exclusions } \\
\end{array}$ & $\begin{array}{c}\text { ASM Survey } \\
\text { Non-response } \\
\text { Cases } \\
\end{array}$ & $\begin{array}{c}\text { Out-of-scope } \\
\text { And Inactive } \\
\text { Cases } \\
\end{array}$ & $\begin{array}{c}\text { Final } \\
\text { Sample }\end{array}$ \\
\hline 1979 & 20,123 & 12,557 & -635 & -23 & -386 & -93 & 11,420 \\
\hline 1980 & 20,123 & 11,935 & -968 & -121 & -326 & -53 & 10,467 \\
\hline 1981 & 20,002 & 11,298 & $-1,439$ & -331 & -317 & -23 & 9,188 \\
\hline 1982 & 18,419 & 17,508 & $-2,610$ & -233 & -592 & -139 & 13,934 \\
\hline 1984 & 20,099 & 18,479 & $-2,599$ & $-1,619$ & -915 & -181 & 13,165 \\
\hline 1985 & 20,099 & 17,213 & $-1,972$ & $-3,013$ & -992 & -85 & 11,151 \\
\hline 1986 & 18,047 & 15,394 & $-1,533$ & $-2,261$ & $-1,194$ & -69 & 10,337 \\
\hline 1988 & 19,505 & 16,585 & $-3,122$ & $-2,053$ & $-1,122$ & -61 & 10,227 \\
\hline TOTAL & 156,417 & 120,969 & $-14,878$ & $-9,654$ & $-5,844$ & -704 & $\mathbf{8 9 , 8 8 9}$ \\
\hline
\end{tabular}


that was imputed [a data flag of "IM" or "M"]. These cases are deemed probable item nonresponse cases. (See below for further details on actual data construction and assumptions made about missing values, item non-response, and so forth.) All told, some 9,654 establishments (of the 106,091) are dropped for (what I deem) difficulties with the variables of interest from the PACE survey, leaving 96,437 establishments.

I then drop cases deemed to be ASM survey non-response cases. My assumption is that these are cases that have their establishment impute flag (EIF) set equal to one. According to an internal memorandum from Timothy Dunne to CES staff dated October 3, 1997: "The full impute flag is usually turned on if the establishment's value of shipments (TVS), salaries and wages (SW), total employment (TE) or cost of materials (CM) is imputed." It is most likely the case that this flag is set because of imputed TVS or CM, since SW and TE are usually available from administrative (tax) records. I assume that this is a reliable indicator of whether or not an establishment returned their ASM form. Note that non-response on (and imputation of) items other than the four mentioned here may still remain. All told, some 5,844 establishments (of the 96,437) are dropped for what I deem ASM survey non-response, leaving 90,593 establishments.

Finally, I eliminate establishments that I would like to deem out-of-scope of the current analysis and/or show signs of inactivity. First, I drop cases that have industry codes in the ASM [OIND] that are outside of manufacturing. I also exclude (the relatively few) establishments located in Alaska and Hawaii, focusing my attention instead on the "mainland" United States, as is common in studies like this one. Finally, I eliminate plants that exhibit signs of inactivity, as defined as those with salaries and wages [SW], total employment [TE], and/or output [TVS+(FIE-FIB)+(WIE-WIB)-VR] equal to zero. All told, some 704 establishments (of the 90,593) are dropped for being out-of-scope to my analysis.

This leaves 89,889 establishments, which serve as the research sample in this paper.

\section{Variables and variable construction}

\section{- Air pollution abatement capital expenditure}

In the 1979-1982 files, I use the variable that the Census Bureau actually tabulated on [AIRCAP] rather than the value reported by the establishment [RAIRCAP], thereby accepting any corrections the Census Bureau may have made to this value. Within the PACE survey response group (see above), I assume away any potential non-response to this item. I therefore set missing values to zero (reflecting the fact that zeros were often not keyed in by the Census Bureau, recognizing however that there may be some item non-responders in this group). In the 1979-1981 files, one cannot distinguish "legitimate" entries of 1 (i.e., \$1000) from "miskeyings" of the "less than $\$ 500$ " box on the survey form. In these three years, I set all cases of AIRCAP=1 equal to zero.

In the 1984-1988 files, I use the variable AIRCAP regardless of what its data flag [AIRCAPF] may indicate, thereby accepting any corrections the Census Bureau may have made to this value. (Capital expenditures are never imputed in the PACE survey.) Within the PACE survey response group (see above), I assume away any potential nonresponse to this item. I therefore set missing values to zero (reflecting the fact that zeros were often not keyed in by the Census Bureau, recognizing however that there may be some item non-responders in this group).

\footnotetext{
${ }^{\dagger}$ Their PACE industry codes [PACEIND], incidentally, indicate that they are in manufacturing. I deem these sufficiently suspicious cases, however, and drop them. See below for a further discussion of industry coding.
} 
- Air pollution abatement operating costs

In the 1979-1982 files, several steps are required to construct this variable. First, within the PACE survey response group (see above), I assume away any potential nonresponse to this item. I therefore set missing values of total pollution abatement operating costs [AOC] equal to zero (reflecting the fact that zeros were often not keyed in by the Census Bureau, recognizing however that there may be some item non-responders in this group). I use the variable that the Census Bureau actually tabulated on [AOC] rather than the value reported by the establishment [RAOC], thereby accepting any corrections the Census Bureau may have made to this value. I (appropriately) set missing values of RAVC, RWVC, and RSWVC (the shares of AOC attributable to air, water, and solid waste pollution abatement, respectively) equal to zero. In the 1979-1981 files, in cases where the shares sum to zero and $\mathrm{AOC}=1$, I set $\mathrm{AOC}$ equal to zero, assuming that these were not "legitimate" entries of 1 (i.e., \$1000) but rather "miskeyings" of the "less than $\$ 500$ " box on the survey form. In all four years, cases where AOC is positive and the shares [RAVC+RWVC+RSWVC] sum to something less than 90 or greater than 110 are dropped (as described above). In the cases remaining, when the shares sum to something other than 100, a new RAVC is calculated, based on its share of the erroneous sum. Finally, air pollution abatement operating costs is computed as the product of AOC (original or modified) and RAVC (original or modified), rounded to the nearest integer.

In the 1984-1988 files, the variable of interest is simply ATOT (i.e., no separation of total pollution abatement operating costs between the three different media is required as in the earlier years). I accept any corrections the Census Bureau may have made to this variable. Here, as opposed to what I am able to do elsewhere, I allow for two types of item non-response. First, cases with positive ATOT are dropped if the data flag ATOTF indicates that the value was imputed ["IM" or "M"]. Second, cases with zero or missing ATOT are dropped if and only if none of the other operating costs [WTOT, HTOT, NHTOT] take on a positive value that wasn't imputed and at least one of the other operating costs actually takes on a positive value that was imputed [a data flag of "IM" or "M"]. I assume away any additional non-response to this item, setting missing values of ATOT equal to zero if necessary (reflecting the fact that zeros were sometimes not keyed in by the Census Bureau, recognizing however that there may still be some item nonresponders in this group). There will be cases here with ATOT $=0$ and a data flag indicating that it was imputed $-\mathrm{a}$ fact that I don't think is significant.

\section{- Total capital expenditure}

An establishment's total capital expenditure is defined by $(\mathrm{NB}+\mathrm{NM}+\mathrm{UE})$ in the ASM files. These variables cover the purchase of all new and used buildings and machinery by the plant in the year, including both pollution abatement capital as well as production capital.

\section{- Total operating costs}

Operating costs, as defined by the PACE survey, include salaries \& wages, parts \& materials, fuel \& electricity, capital depreciation, equipment leasing, and services \& contract work. An establishment's total operating costs, therefore, is best measured by the ASM variables: $\mathrm{SW}, \mathrm{CP},(\mathrm{CF}+\mathrm{EE}),(\mathrm{BD}+\mathrm{MD}), \mathrm{MR}$, and $\mathrm{CW}$, respectively. 
There are two important qualifications to note here. First, the cost of purchased services is not adequately captured (by $\mathrm{CW}$ ) in the ASM. Therefore, operating costs, as a concept, will be under-measured here relative to what is found in the PACE survey. Second, capital depreciation (BD+MD) and equipment leasing (MR) were not asked in the 1986 and 1988 ASM. These variables in these years were imputed by the Census Bureau, based on prior years' data.

\section{- Total employment}

An establishment's total employment is defined by TE in the ASM files. This variable is the number of non-production workers during the pay period that includes March 12th, plus the average number of production workers across the four pay periods that include the 12th of March, May, August, and November.

\section{- Belongs to a multi-unit firm}

An establishment is a member of a multi-unit firm if its ID begins with a number other than zero. If the ID begins with a zero, that establishment is the only location at which that firm produces.

- Age of establishment

The age of an establishment can be roughly approximated by the year it made its first appearance in the Census of Manufactures (conducted in 1963, 1967, 1972, 1977, 1982, 1987, 1992, and 1997). This is done by comparing the PPNs in the ASM files against the PPNs in the various Census files. About $2.3 \%$ of the cases do not appear in any of the Census of Manufactures. These are assumed to be new births that failed to survive to the next Census. Their first Census appearance was imputed to be that next Census after their PACE/ASM appearance. In exceedingly rare cases $(<0.02 \%)$, the first Census appearance was the second Census after an establishment's PACE/ASM appearance. These cases were reset to have their first Census appearance be the first Census after their PACE/ASM appearance.

I use an establishment's first appearance in the Census of Manufactures to assign it to one of five "generations". Plants in the PACE/ASM in 1979-1982 are said to belong to the youngest generation if they made their first Census appearance in 1982. They are " 1 generation old" if they made their first Census appearance in 1977, " 2 generations old" if they made their first appearance in 1972, "3 generations old" if their first appearance was in 1967, and "4 or more generations old" if they made their first appearance in the 1963 Census. Similarly, plants in the 1984-1986 PACE/ASM belong to the youngest generation if they made their first Census appearance in 1987, and are 1, 2, 3, or 4+ generations old if they first appeared in 1982, 1977, 1972, or 1967/1963, respectively. For plants in the $1988 \mathrm{PACE} / \mathrm{ASM}$, their generation depends on whether their first appearance was in 1992, 1987, 1982, 1977, or 1972/1967/1963, respectively.

\section{- Industry}

There are two alternative sources for an establishment's 4-digit Standard Industrial Classification (SIC) code: OIND is the ASM files and PACEIND in the PACE files. Both of these industry codes are on the 1972 SIC basis, with the exception of OIND in the 1988 ASM, which is on the 1987 SIC basis. 
In classifying establishments as "high emitters" (see below), I employ OIND. When controlling for industry effects in my regression analyses, I use OIND for plants in 19791986 but PACEIND for establishments in 1988. This ensures that the industry code for all establishments is on the 1972 SIC basis.

Alternatively, I exclusively used PACEIND to classify high emitters and for industry fixed effects. After recoding PACEIND for some $0.1 \%$ of cases (where the existing industry code is not among the 449 legitimate 1972 4-digit industry codes) I find that PACEIND and OIND differ in 7.4\% of the 79,662 establishments in 1979-1986 (the years in which PACEIND and OIND are both on the 1972 SIC basis). Empirical results seem relatively robust to these differences.

\section{Defining "high emitters"}

Data, by 4-digit SIC, on the number of establishments with emissions exceeding threshold amounts, by criteria air pollutant, come from Source SIC Reports, derived from information contained in the EPA's Aerometric Information Retrieval System (AIRS) Facility Subsystem (AFS). The threshold amounts of emissions (set by the EPA, determining a facility's inclusion in the AFS) are: 100 tons per year for $\mathrm{VOC}, \mathrm{NO}_{2}, \mathrm{SO}_{2}$, and particulates; 1000 tons per year for $\mathrm{CO}$; and 5 tons per year for lead.

The reports used in this current study were downloaded from http://www.epa.gov/airsdata/ srcsic.htm in May 2000, representing the best available information as of April 28, 2000. Sources are not required to provide pollutant emissions estimates to the EPA every year. The values in the AFS, therefore, are the latest available for each facility. Estimates of emissions, for each source, are based on a normal operating schedule and "includes the effects of installed pollution control equipment and regulatory restrictions on operating conditions."

The Source SIC Reports, for the most part, employ the industry definitions found in the 1987 Standard Industrial Classification manual. The establishments in my sample, however, with the exception of the 1988 plants, are classified according to the 1972 SIC definitions. Therefore, in order to match the industry data in the Source SIC Reports to my establishment data, I need to convert the former from the 1987 SIC basis to the 1972 SIC basis. For many industries this is rather straightforward: some industries were not redefined between the two SIC schemes; others map into a single 1972 SIC. For industries where there is no unique mapping of a 1987 SIC into a 1972 SIC, however, a decision must be made on how to distribute the data to the various 1972-based industries. Here, I use the employment-weighted SIC concordance from 1987, capturing the relative importance of each 1972 SIC in a new 1987 SIC, at the time the industry classification scheme was redefined.

The result here is a file containing the number of establishments exceeding threshold emissions, by criteria air pollutant, for each of the 449 manufacturing industries (1972 SIC definitions). A similar file, for each of the 459 manufacturing industries (1987 SIC definitions), was also constructed. This required the conversion of a small number of 1972 SICs to the 1987 basis. The assignment of facilities from 3-digit industries to 4-digit industries (as well as some other minor modifications) also needed to occur in the construction of these files.

These industry data are then merged to the plant-level data using the industry code in the ASM files (OIND). For establishments in 1979-1986, OIND is on the 1972 SIC basis. For plants in 1988, OIND is on the 1987 SIC basis. An establishment is then defined as a "high emitter" (or not) of each criteria air pollutant if its industry has at least a certain number of 
establishments emitting over the threshold amount. ${ }^{-}$For CO, particulates, and lead, industries with 1 or more establishments above the respective thresholds are considered high emitters. For $\mathrm{NO}_{2}$ and $\mathrm{SO}_{2}$, industries with 2 or more establishments above the threshold are considered high emitters. For VOC, industries with 4 or more establishments above the threshold are considered high emitters. These particular cutoffs were chosen so that no more than $50 \%$ of the establishments in the sample are designated a high emitter of any pollutant. Table 3 shows the exact percentages. The list of industries classified as high emitters of the various pollutants is available from the author.

\section{County non-attainment statuses}

Every year, since 1978, each county in the United States is officially designated as being either in attainment or non-attainment of the NAAQS for each criteria air pollutant. This information is published each July in the Code of Federal Regulations (Title 40, Part 81, Subpart C). I have entered these data in by hand (off of microfiche copies) for years 1978-1987.

An establishment is deemed to have been in a county with more stringent regulation vis-àvis a particular pollutant, if the county was classified in non-attainment of the NAAQS for that pollutant in the pfior calendar year (i.e., the 1978 designation affects APA expenditures in 1979, and so forth) $\square^{\dagger}$ For $\mathrm{SO}_{2}$ and TSP, there are also secondary NAAQS standards in addition to the usual primary standards. Secondary standards are meant to "protect public welfare including protection against decreased visibility, damage to animal, crops, vegetation, and buildings" while primary standards are meant to protect public health. If either of these standards was violated, I define the county to be in non-attainment. Counties that "cannot be classified" are assumed to be in attainment of NAAQS. In some states, for some pollutants, non-attainment areas are sometimes described in terms of sub-county divisions (e.g., towns, cities, or zones) or by a combination of manmade landmarks (e.g., highways), topographical features (e.g., rivers or mountains), and coordinates. If any portion of a county was designated as being in nonattainment, I've coded the entire county as being in non-attainment. Additional detail regarding the coding of county non-attainment status (including assumptions made, etc.) is available from the author.

County non-attainment status vis-à-vis lead $(\mathrm{Pb})$ and nitrogen dioxide $\left(\mathrm{NO}_{2}\right)$ is not considered in my empirical analyses. During the time period studied here, county lead nonattainment status was not listed in the CFR along with the other criteria pollutants, and I was otherwise unable to locate this information. I ignore county $\mathrm{NO}_{2}$ non-attainment status here (a) because during the time period being studied, no more than a dozen counties were ever in $\mathrm{NO}_{2}$

\footnotetext{
$\dagger$ The assumption here is that the presence of the industry in the right tail of the facility emissions distribution says something about the emissions of the typical plant in the industry. In principle, a better indicator here might be the proportion of an industry's establishments that are in the right tail of the distribution, but there are issues in constructing this measure with the data at hand.

${ }^{\dagger}$ For particulates, emissions of total particulate matter (PT) is used rather than particulate matter less than 10 micrometers $\left(\mathrm{PM}_{10}\right)$, which is also available in AIRS.

tit This, of course, is not the only possible specification. Within the non-attainment group, a distinction might be made for counties that have always been in non-attainment, if one believes that persistence indicates the severity of the problem and a heightened stringency of regulation. Alternatively, we may be interested in counties that were ever in non-attainment. After all, counties that have brought themselves into attainment may not necessarily loosen regulatory controls. Henderson (1996) considers a county's recent history — in particular, whether or not the county has been in non-attainment in any of the past three years (including the current). Experimentation with alternative definitions will not be conducted here in this paper.
} 
non-attainment and (b) since ground-level ozone $\left(\mathrm{O}_{3}\right)$ forms through the interaction of both $\mathrm{NO}_{2}$ and VOC emissions, ozone non-attainment status is actually relevant to high emitters of both pollutants (and is treated as such in my empirical analyses). Incidentally, these dozen $\mathrm{NO}_{2}$ nonattainment counties were also always in ozone non-attainment at the same time. 